\title{
1 Combinatorial CRISPR screening reveals functional buffering in autophagy
}

\section{AUTHORS}

6 Valentina Diehl (1, \#), Martin Wegner (1, \#), Paolo Grumati (1, 6, \#), Koraljka Husnjak (1), Simone

7 Schaubeck (1), Andrea Gubas (1), Varun Jayeshkumar Shah (1), Felix Langschied (2), Alkmini

8 Kalousi (1), Ingo Ebersberger (2), Ivan Dikic (1, 3-5, *), and Manuel Kaulich (1, 3-4, *)

\section{AFFILIATIONS}

111 - Institute of Biochemistry II, Faculty of Medicine, Goethe University Frankfurt, Theodor-Stern-Kai 7,

1260590 Frankfurt am Main, Germany.

132 - Applied Bioinformatics Group, Institute of Cell Biology and Neuroscience, Goethe University Frankfurt, 14 Germany.

153 - Frankfurt Cancer Institute, Frankfurt am Main, Germany.

164 - Cardio-Pulmonary Institute, Frankfurt am Main, Germany.

175 - Buchmann Institute for Molecular Life Sciences, Goethe University Frankfurt, Max-von-Laue-Str. 15, 1860438 Frankfurt am Main, Germany.

196 - current address: Telethon Institute of Genetics and Medicine, Via Campi Flegrei 34, 80078 Pozzuoli

20 (NA), Italy

$21 \quad$ \# - equal contribution

22 *-correspondence: Manuel Kaulich, kaulich@em.uni-frankfurt.de, and 


\section{ABSTRACT}

25 Functional genomics studies in model organisms and human cell lines provided important insights into gene functions and their context-dependent role in genetic circuits. However, our functional understanding of many of these genes and how they combinatorically regulate key biological processes, remains limited. To enable the SpCas9-dependent mapping of gene-gene interactions in human cells, we established 3Cs multiplexing for the generation of combinatorial gRNA libraries in a distribution-unbiased manner and demonstrate its robust performance. The optimal number for combinatorial hit calling was 16 gRNA pairs and the skew of a library's distribution was identified as a critical parameter dictating experimental scale and data quality. Our approach enabled us to investigate 247,032 gRNA-pairs targeting 12,736 gene-interactions in human autophagy. We identified novel genes essential for autophagy and provide experimental evidence that gene-associated categories of phenotypic strengths exist in autophagy. Furthermore, circuits of autophagy gene interactions reveal redundant nodes driven by paralog genes. Our combinatorial 3Cs approach is broadly suitable to investigate unexpected gene-interaction phenotypes in unperturbed and diseased cell contexts.

\section{INTRODUCTION}

41 Combinatorial gRNA expression (gRNA multiplexing) for related or orthogonal CRISPR

42 applications enable the comprehensive characterization of genetic interactions in human cells.

43 Several methods are available to support the generation of combinatorial gRNA expression systems, 1) restriction enzyme-based ${ }^{1-4}, 2$ ) golden-gate assembly ${ }^{5-8}, 3$ ) gateway-dependent ${ }^{9,10}$, as well as 4) recombination-dependent gRNA cloning techniques ${ }^{11}$. These systems are widely used to clone gRNA sequences in combination with RNA polymerase III promoters, resulting in arrayed gRNA-expression cassettes. In contrast, RNA polymerase II promoters generate RNA transcripts that can contain multiple gRNA sequences, although these transcripts require posttranscriptional processing to yield functional gRNA sequences and are currently limited to Cas 12 applications $^{12,13}$. The most widely used Cas-nuclease thus far is SpCas9, though a cloning-free gRNA multiplexing concept for Cas9 gRNAs is currently lacking, because repetitive and homologous sequences are unstable in lentiviral vectors ${ }^{14-16}$, rendering them less suited for largescale combinatorial screening.

54 Concomitant mutations in two genes can yield unexpected phenotypes with respect to each 55 gene's individual phenotype ${ }^{17}$. Synthetic lethality as the most extreme combinatorial phenotype 
57 synthetic lethal gene pair with clinical relevance is poly (ADP-ribose) polymerase (PARP) 58 inhibition in the context of defective BRCA1 or BRCA2 genes ${ }^{15,21,22}$. Additionally to this DNA59 damage repair-related example, synthetic lethal interactions have been identified in combinatorial 60 gRNA CRISPR screens, including the apoptotic genes BCL2L1 and MCL1 or BCL2L1 and $61 B C L 2 L 2^{16,23,24}$, the mitogen-activated protein kinases 1 and $3\left(M A P K 1\right.$ and MAPK3) ${ }^{1}$, as well as the $62 \mathrm{PIP}_{3}$ phosphatase $P T E N$ and the mammalian target of rapamycin $M T O R^{25,26}$. To perform pairwise 63 hit calling in CRISPR screens, two methods are currently established: 1) a variational Bayes 64 approach (GEMINI) ${ }^{27}$, and 2) the difference of expected to measured $\log _{2}$-fold-changes (dLFC) in 65 which the expected $\log _{2}$-fold-change of a gRNA combination is the sum of the $\log _{2}$-fold-changes 66 of each individual gRNA when partnered with control gRNAs ${ }^{16,24}$. These computational 67 approaches have been applied to negative CRISPR screens. However, with combinatorial gRNA 68 CRISPR screens being mostly performed in drop-out conditions, we lack knowledge of their performance for Cas9-based combinatorial gRNAs in positive or FACS-based phenotypic enrichment screens.

Bulk and selective autophagy are tightly regulated processes that target cellular material for lysosomal degradation and their misregulation culminates in abnormal cell growth and cell death with implications in various human diseases ${ }^{28,29}$. Rationally-engineered fluorescent reporter systems in combination with high-throughput CRISPR screens facilitated the systematic categorization of genes based on their essentiality in autophagy. As such, the transmembrane protein 41B, as well as the ubiquitin-activating enzyme UBA6, and the hybrid ubiquitin-conjugating enzyme/ubiquitin ligase BIRC6 were recently identified as important players in the autophagy network $^{30-35}$. Despite the mapping of essential genes, CRISPR screens paired with fluorescent autophagic reporters revealed the stress-dependent regulation of autophagy-related genes ${ }^{36-38}$, and provided mechanistic insights into the gene specificity in bulk and selective autophagy by identifying PARKIN regulators and the ANT complex as essential components for mitophagy ${ }^{39,40}$. In combination with proximity biotinylation-coupled mass spectrometry, CRISPR screens also contributed to a spatial proteogenomic understanding of PARK2-dependent mitophagy ${ }^{41}$. Thus, unbiased CRISPR approaches coupled to fluorescent reporters and mass spectrometry are valuable approaches to identify vulnerabilities in bulk and selective autophagy for the treatment of neurodegenerative diseases and cancer ${ }^{42-44}$.

87 Here, we add to our previous work and describe the SpCas9-based 3Cs multiplexing technology

88 for the generation of dual combinatorial (multiplexed) gRNA libraries with diversities of up to 89 several hundreds of thousands of gRNA combinations ${ }^{45}$. In addition to identifying critical technical 90 parameters, we generated a combinatorial library targeting the human autophagy network and 
91 performed a fluorescent reporter-based FACS enrichment screen to identify hitherto

92 uncharacterized single genes and gene interactions essential for autophagy. Our 3Cs multiplexing

93 technology is widely applicable and can serve as a general tool for the identification of context-

94 dependent gene interactions at any scale.

\section{RESULTS}

\section{Cs multiplexed Cas9 gRNA libraries}

To expand on our 3Cs technology and enable Cas9 gRNA multiplexing, we generated a lentiviral Cas9-gRNA expression plasmid (pLenti-Multiplex) by placing a human 7SK (h7SK) promoter upstream of a previously engineered Cas9-tracrRNA followed by a human U6 (hU6) promoter upstream of a wildtype Cas9-tracrRNA sequence ${ }^{46,47}$. Both gRNA cassettes contain a gRNA placeholder sequence encoding for I-Ceul or I-Scel restriction enzyme sites, respectively (Figure $1 \mathrm{~A})^{45}$. Furthermore, in addition to a puromycin selection cassette, the plasmid contains an $\mathrm{f} 1$ bacteriophage origin of replication sequence in sense direction, supporting the CJ236 bacteria and M13KO7 bacteriophage-dependent generation of dU-containing single stranded (ss) DNA (Figure 1A, Supp. Figure 1A). In contrast to single gRNA 3Cs reactions, 3Cs multiplexing is performed in the presence of two gRNA-encoding oligonucleotide pools of which each contains unique 5' and 3' homology sequences for annealing to the h7SK or hU6 gRNA cassettes, thereby generating hetero-duplex dU-containing double stranded (ds) DNA that contains all possible gRNA combinations of the two oligo pools (Figure 1A). A coverage-based electroporation into dut/ung-positive bacteria results in template-strand depletion and combinatorial gRNA-containing dsDNA. To test this concept, we designed two gRNA-encoding oligo pools each containing 50 gRNA sequences targeting GFP (pool-1) or mCherry (pool-2) and used them to generate a combinatorial gRNA library, in addition to the respective single gRNA libraries (Figure 1B). Based on the typical three-band pattern of $3 \mathrm{Cs}$ dsDNA ${ }^{45,48}$, we observed similar yields and quality of dUcontaining hetero-duplex dsDNA after applying two pools in a single 3Cs reaction when compared to either pool alone (Supp. Figure 1A). Digesting the final libraries with I-Ceul and I-Scel enzymes confirmed the exclusive presence of gRNA-containing plasmids (Figure 1C). Paired-end nextgeneration sequencing (NGS) revealed all three libraries to be complete with distribution skews of 1.56, 1.17, and 1.53 for GFP, mCherry, and GFP+mCherry, respectively (Figure 1D, Supp. Figure 1B-C). Most importantly, when packaged into lentiviral particles and transduced into GFP and mCherry-expressing hTERT-RPE1(Cas9) cells, the combinatorial GFP+mCherry library induced the simultaneous depletion of GFP and mCherry fluorescence while both single libraries 
selectively depleted either GFP or mCherry fluorescence (Figure 1E). Thus, 3Cs multiplexing generates tightly distributed combinatorial gRNA libraries that are functional in human cells.

\section{Cs multiplexing decouples sequence distribution and diversity}

128 Current combinatorial gRNA libraries contain 9 to 18 gRNA pairs per gene-pair ${ }^{3,15,24}$, thus, a robust 129 technology must generate large pairwise gRNA diversities without compromising reagent quality.

130 We therefore investigated whether $3 \mathrm{Cs}$ multiplexing, similar to single gRNA $3 \mathrm{Cs}^{45}$, would 131 decouple library quality from library size. To this end, we designed four oligonucleotide pools per 132 gRNA cassette in which one, two, three, or four nucleotide positions within a non-human-target 133 (NHT) gRNA sequence were randomized to mimic increasing combinatorial gRNA diversities $(1 \mathrm{~N}$, $1344 * 4=16$ combinations; $2 \mathrm{~N}, 16 * 16=256$ combinations; $3 \mathrm{~N}, 64 * 64=4,096,4 \mathrm{~N}, 256 * 256=65,536$ 135 combinations). NGS confirmed the libraries to be complete and evenly distributed with areas 136 under the curve (AUC) between 0.59 and 0.69 (Figure 2A, Supp. Figure 2A-B). Notably, we 137 identified the distribution skew to be very narrow with ranges from $1.1(1 \mathrm{~N})$ to $1.49(4 \mathrm{~N})$, values 138 mostly unmatched even with single gRNA libraries (Supp. Figure 2A-B). Thus, 3Cs multiplexing 139 is a highly robust method to generate combinatorial gRNA libraries with large sequence diversities.

\section{Library distribution skew influences experimental scale}

143 Higher replicate correlation was computationally demonstrated to correlate with smaller library 144 distribution skew and higher library representation ${ }^{49}$. Thus, we aimed at experimentally investigating to what extent a combinatorial gRNA library's distribution skew contributes to hit calling accuracy by generating combinatorial libraries with artificially distorted gRNA representations and screening them in different coverages. We selected a panel of 20 genes equally divided in 10 core essential (CE) and 10 tumor-suppressor genes (TSGs) and designed 4 gRNAs per gene. As internal controls, we choose 80 pre-validated NHT sequences ${ }^{50,51}$. We designed two 3Cs oligo pools: pool-1 contained CE and TSG-targeting gRNAs for h7SK and hU6 cassettes in equal ratios ( $2^{*} 80$ gRNAs), while pool-2 consisted exclusively of NHT gRNA sequences in equal ratios for h7SK and hU6 cassettes (2*80 gRNAs). To generate artificially distorted library skews, we mixed both pools in equimolar ratios (1:1), and in ratios of increasing

154 NHT sequence-molarity (1:10 and 1:100) and applied them to 3Cs multiplexing. NGS confirmed 155 an increased fraction of NHT reads in the 1:10 and 1:100 libraries (Figure 2B, Supp. Figure 2C), 156 and revealed an AUC value for the 1:1 library of 0.65 , while the 1:10 and 1:100 libraries contained 157 increased AUC values of 0.85 and 0.9 , respectively (Figure 2C). Most importantly, library 
distribution skews increased from $1.2(1: 1)$ to 2.4 (1:10) and 13.46 (1:100) (Supp. Figure 2D), demonstrating that final $3 \mathrm{Cs}$ library quality is coupled to an oligo pool's distribution. Using these libraries in representations of 20 - and 200 -fold, we evaluated a total of 153,600 pairwise gRNA-knockouts in human hTERT-RPE1(Cas9) cells in biological replicates. Pairwise guide and gene-level counts correlated well for individual libraries and biological replicates (gene level, 20x - 1:1, Pearson $r=0.96 ; 1: 10$, Pearson $r=1 ; 1: 100$, Pearson $r=0.79-1 ; 200 x-1: 1$, Pearson $r=0.91-0.98 ; 1: 10$, Pearson $r=0.96-0.97 ; 1: 100$, Pearson $r=0.98-1$; Supp. Figure 3AB). We next analyzed the difference of $\log _{2}$ fold changes (log2FC) in our screens by means of separating essential genes from non-targeting controls and computed Cohen's D statistics (quality score (QS)), a value recently introduced to quantify screen quality ${ }^{52}$. Quality scores for the 1:1 library in both tested coverages were very high with 2.95 and 3.25 for 20 - and 200-fold, respectively (Figure 2D). However, a decline in screen quality appeared when library distribution skews increased above 2 (1:10 library, 20x - QS: 1.5, 200x - QS: 2.68; 1:100 library, 20x - -0.44, 200x - -1.17; Figure 2D).

We next assessed if higher experimental coverage was able to rescue wider library distribution skews by identifying essential gene pairs with MAGeCK analyses and cut-off filters set to FDR $\leq 10 \%$ and $\log 2 \mathrm{FC}<-0.5$. Strikingly, the number of retrieved gene pairs per library distribution skew was nearly identical between 20- and 200-fold coverages (Figure 2E), suggesting that CRISPR libraries with narrow distribution skews can be screened at minimal experimental coverage without compromising data quality. Furthermore, these analyses also suggest that higher experimental coverage is likely insufficient to rescue wider library distribution skews. Therefore, a library's distribution skew is a critical parameter that should be considered when designing combinatorial CRISPR libraries and screens.

\section{The optimal number of pairwise gRNAs for statistical gene-interaction calling} The number of gRNAs per gene has a profound impact on statistical hit calling ${ }^{53,54}$, thus we analyzed the concordance of essential pairwise genes identified across the two experimental coverages with increasing numbers of pairwise gRNAs. We down-sampled the 1:1 data sets and generated a series of read count tables containing between 1 and 16 randomly chosen gRNA 187 pairs for each gene combination and performed MAGeCK analyses with cut-off filters at 188 FDR $\leq 10 \%$ and $\log 2 \mathrm{FC} \leq-0.5^{53,54}$. A total of 100 essential gene interactions exist within both 189 libraries (10*10 essential genes), and as expected, 16 pairwise gRNAs per gene interaction 190 consistently retrieved the largest number of statistically significant essential gene interactions 191 (200x - 70\%, 20x - 72\%) (Figure 2F). However, performance differences became evident in the 
down-sampled libraries containing up to 4 pairwise gRNAs with $13 \%$ and $20 \%$ paired gene interactions identified, for 200 and 20-fold library representations, respectively (Figure 2F). Strikingly, the performance increased noticeably in both coverages up until 13 pairwise gRNAs from which on the performance plateaued (Figure $2 \mathrm{~F}$ ). These results are consistent with previous observations for single gRNA SpCas9-dependent CRISPR screens, in which 4 to 6 gRNAs per gene have been identified for robust statistical hit calling ${ }^{55}$. Assuming the generation of gRNA number-balanced libraries, our observations identify 16 pairwise gRNAs $(4 * 4)$ as the optimal number for statistical gene-interaction calling.

\section{Single and inherent-single gRNA enrichment screens are complementary}

202 Pairwise gRNA screens have been applied to phenotypes related to cell viability (drop-outs), but their performance in enrichment-based screens remains elusive. To address this question, we identified parameters to investigate pairwise gene interactions in the self-degrading process of human autophagy by LC3-coupled fluorescent-dependent enrichment screening. We used the established GFP-LC3-RFP reporter construct to generate a monoclonal hTERT-RPE1 reporter cell line and confirmed reporter functionality by mTOR inhibition (Torin1 treatment) alone and in combination with the autophagy inhibitor Bafilomycin (Supp. Figure 4A) ${ }^{56}$. Next, we assembled a literature-curated list of 192 "extended autophagy" genes that included, among others, autophagyrelated genes (ATGs), autophagy receptors, as well as transcription factors and deubiquitinases,

211 plus 7 core essential genes as negative controls. To generate a combinatorial gRNA library, we 212 designed a second oligo pool, named "core autophagy", consisting of 64 commonly considered 213 core autophagy genes (Figure 3A, core autophagy, Supp. Table 1). For each gene, we designed 2144 gRNA sequences using rule set 2 and added $10 \%$ NHT sequences to each pool ${ }^{51}$, resulting in 215 a total of 876 gRNAs in the "extended autophagy" pool and 282 gRNAs in the "core autophagy" 216 pool, together generating 247,032 pairwise gRNAs (Figure 3A). We applied the extended 217 autophagy pool alone and in combination with the core autophagy pool to $3 \mathrm{Cs}$ reactions and 218 generated the single gRNA and pairwise gRNA libraries, respectively. NGS revealed narrow 219 distribution skews (single library, skew ratio=1.22; multiplex library, skew ratio=1.69) and AUC 220 values of 0.65 and 0.68 (Supp. Figure 4B-D), supporting our previous observation that $3 \mathrm{Cs}$ 221 multiplexing is a highly robust method for the generation of combinatorial gRNA libraries.

222 To benchmark our screening approach, we first applied the single autophagy library to screen for 223 genes essential for Torin1-induced autophagy (Figure 3B). In order to reduce the number of false224 positive hits, we chose stringent FACS-gating criteria that only enriched cells in which autophagy 225 was completely blocked (Figure 3C, single screen). Importantly, proliferative effects as a 
consequence of gene knockouts are a source of false-positive hit calling in enrichment screens, especially in TP53-positive cells. Thus, we collected a coverage-based cell sample at the day of FACS sorting to correct for positive or negative proliferative effects (Figure 3B). Guide RNA and gene level correlations between pre- and post-FACS samples were high among biological replicates (guide level, Pearson r=0.87; gene level, Pearson $r=0.97$; Supp. Figure 5A-B), thus we applied MAGeCK and retrieved 12 significantly enriched genes with log2FC between 3.76 and 9.12 with FDR $\leq 10 \%$ (Supp. Table 2). Importantly, our benchmark screen successfully retrieved previously identified core autophagy genes required for mTOR-induced autophagy and correctly

234 assigned their function to bulk autophagy by means of a positive log2FC between pre- and post-

235 FACS conditions (Figure 3D) $32,33,35,39,40,57,58$.

236 Next, we dramatically scaled up to perform the autophagy multiplex screen at a 20 -fold coverage 237 at pre- and post-FACS time points, investigating a total of 1,235,160 pairwise gRNAs. Guide RNA and gene level correlations between pre- and post-FACS samples were high among biological triplicates: gRNA level, pre-FACS, Pearson r=0.99; post-FACS, Pearson $r=0.58-0.69$; gene level, pre-FACS, Pearson r=0.99; post-FACS, Pearson r=0.77-0.84 (Supp. Figure 5A, C-D). During the course of FACS sorting, we noticed a population of cells that was absent from single gRNA transduced cells and extended our sorting strategy to also investigate cells from this "high-gate" (Figure $3 \mathrm{C}$ ). We first assessed the nature of the high-gate cell population and identified the majority of reads to account for ATG4B-dependent gRNA pairs (post-FACS 1, 86.94\%; postFACS 2, 78.03\%; post-FACS 3, 75.53\%) (Supp. Figure 5E). To permit its function, ATG4 cleaves the LC3-reporter and paired ATG4 gene knockouts likely interfere with reporter functionality and served as additional controls to validate our library and screening strategy ${ }^{56}$.

249 (NHT:NHT), 2) extended autophagy with control (gene:NHT), 3) control with core autophagy 250 (NHT:gene), and 4) extended autophagy with core autophagy (gene:gene) (Figure 3A). Thus, we next assessed the concordance of identified single genes essential for autophagy induction between our single autophagy benchmark screen and the extended autophagy gRNAs paired with control guides in the combinatorial screen. We applied MAGeCK to compare pre- and postFACS time points and identified 10 significantly enriched genes with log2FC between 1.53 and 2.75 and FDR $\leq 10 \%$ (Figure 3E). Screen concordance was high with 7 jointly identified genes,

256 though each experiment successfully identified unique genes essential for bulk autophagy 257 induction (Figure 3D-E, unique hits in blue-bold). Importantly, the jointly identified genes ATG9A, 258 RB1CC1, ATG12, ATG7, ATG3, and ATG16L1 as well as the unique hit genes ATG101, ATG10, 259 ATG13, ATG5, ATG14 and TMEM41B could be successfully validated by targeting each gene 
with a newly designed single gRNA, for which gRNA performance during the course of validation was quantified by TIDE analysis (Figure 3F). Screen concordance could be further improved to 11 jointly identified genes by filtering for p-values below 0.05 and simultaneously relaxing the FDR, although the number of uniquely identified genes per screen increased accordingly to 8 and 7 for dedicated single and inherent single screens, respectively (Supp. Figure 6A-B). This demonstrates that dedicated single and inherent-single autophagy screens are complementary and that either one alone was insufficient to identify all true-positive hits.

\section{Synergistic gene pairs essential for autophagy}

269 Targeting single genes with two gRNAs has been shown to improve knockout rates ${ }^{59}$, we therefore investigated the consistency of this phenotype within our combinatorial data set. As expected, we repeatedly observed a higher log2FC for combinatorial-gRNA targeted genes (Supp. Figure 7A), particularly for genes that we identified and validated as essential for autophagy (Supp. Figure 7B). Next, we assessed pairwise gene interactions essential for autophagy induction by applying MAGeCK to pre- and post-FACS samples. This identified a total of 3645 significant gene pairs, of which 187 gene pairs accounted for pairs in which both genes were jointly or uniquely identified as single essential for autophagy (Figure 4A, D). 3245 gene pairs accounted for gene pairs in which one or the other gene was identified as being essential for autophagy (Figure 4B, D), and 213 gene pairs consisted of genes for which neither partner gene was identified as being essential for autophagy (Figure 4C, D). Interactions between the majority of identified gene pairs are driven by a single gene that is essential for autophagy and interactions between non-essential autophagy genes are rare, which is well in agreement with previous work that mapped genetic interactions in Saccharomyces cerevisiae ${ }^{60}$. To corroborate our findings, we set up arrayed dual gene-targeting validations in which either one gene or both genes were essential for autophagy induction. As expected, targeting two essential autophagy genes consistently increased the fraction of cells in which autophagy was blocked (Figure 4E), and pairing an essential autophagy gene with an autophagy-related but non-essential gene also increased the fraction of cells in which autophagy was blocked (Figure 4F). Interestingly, among the non-essential:non-essential hits, we identified ULK1, AMBRA1, WIPI2, and BECN1 in combinations with control gRNAs, suggesting these genes to be essential for autophagy on their own, a conclusion supported by the literature ${ }^{33,57}$. They have likely missed our attention in the

291 single gRNA CRISPR screens due to their relatively mild phenotype compared to the other 292 autophagy essential genes. Indeed, in arrayed single gRNA validations, the depletion of ULK1 293 and WIPI2 alone blocked autophagy, although the phenotype was milder when compared to 
ATG9A depletion that we identified as a strong hit (Figure 4G). This suggests, in the context of hTERT-RPE1 cells and Torin1-induced autophagy, that gene-associated categories of phenotypic strengths exist in autophagy. Most interestingly, among others, we identified several gene pairs capable to block autophagy induction (Figure 4C). We noted several gene pairs in which one gene is either of the Ras-related protein family (RABs) as well as several pairs that included ATG2A. Among these interactions we identified ATG2A-ATG2B for which the validation in arrayed dual-gene knockout conditions confirmed the blockage of autophagy only when both genes are interfered with, experimentally verifying these genes as functional redundant homologues (Figure 4G).

303 Four mathematical definitions of genetic interactions have been proposed previously (Product (MULT), Additive (SUM), Log (LOG), and Min (MIN)) ${ }^{17}$. We also included a Max (MAX) definition and applied all models to identify combinatorial phenotypes that are surprising with respect to each gene's single phenotype. Genetic interactions are rare ${ }^{60}$, we thus computed the deviation of observed paired-knockout phenotypes from their expectation (delta log2FC, $\Delta \log 2 \mathrm{FC}$ ) and identified the MAX model to fit our combinatorial autophagy data set best (Figure $4 \mathrm{H}$ ), especially when only considering genes that we identified to be essential for autophagy for which the deviation from the expectation is low (Supp. Figure 7C). In total, we identified 3665 genetic interactions that we filtered by significance $(p \leq 0.05)$ and $\Delta \log 2 F C s$ above their single standard deviation, resulting in a total of 57 (1.6\%) high confidence synergistic gene pairs (Figure 4I, yellow dots, Supp. Table 3). To better depict relations among these gene interactions, we performed a network analysis and identified 5 network components (1, 36 nodes; 2, 10 nodes; 3,5 nodes; 4, 3 nodes; and 5; 4 × 2 nodes) (Figure 4J). Most importantly, we identified functional redundancy in autophagosome assembly (ATG2A/B), phosphatidylinositol phosphorylation (PIK3CA/PI4K2A), phagosome-lysosome fusion (RAB7A/5A and RAB7B/5A), and selective autophagy (PARK2 with

318 PLEKHM1 and CALCOCO2, OPTN with PINK1, and PARK7 with FAM134B) (Figure 4J).

319 Furthermore, we identified DNA Damage-Regulated Autophagy Modulator Protein 1 (DRAM1)320 dependent interactions with mitochondrial PINK1 and PARK2 for which the DRAM1-dependent 321 induction of autophagy was shown to be dependent on mitochondrial protein synthesis 322 inhibition $^{61}$. Thus, our identified gene interactions likely resemble functional nodes within the 323 human autophagy circuit in which redundancy exists and point towards gene paralogs as a critical 324 factor in generating redundancy in autophagy. 
327 Several technologies are available to generate combinatorial gRNA-containing plasmids and 328 libraries. They mostly depend on open plasmid DNA and PCR amplified gRNA-encoding 329 oligonucleotide pools, resulting in cloning-artefacts and sequence biases. Our newly developed 3303 Cs multiplexing technology functions with single stranded template plasmids and oligonucleotide 331 pools, thereby circumventing additional and unintended sequence representation dispersions.

332 Passaging coverage and CRISPR library distribution skew have recently been computationally 333 predicted to be critical factors for data quality ${ }^{49}$. Indeed, our experimental analysis of combinatorial 334 libraries with varying distribution skews, applied with different passaging coverages, supports this 335 prediction and identifies a distribution skew of below 2 as a threshold enabling passaging 336 coverages below 100-fold. Furthermore, we provide experimental evidence that combinatorial 337 libraries with distribution skews above 2 should be screened with passaging coverages $\geq 200$ to 338 compensate for the library's sequence dispersion. However, rescuing libraries with large distribution skews $(\geq 10)$ by applying high passaging coverage is likely going to fail, as the

342 Combinatorial gRNA screens are more frequently performed to identify gene pairs essential for cell viability. However, as of today, no combinatorial gRNA screen in combination with pathwayspecific fluorescence reporters has been performed. While the inherent single gRNA phenotypes appear to be sufficient in the context of cell viability screenings, we show that dedicated and inherent single gRNA screens are complementary for combinatorial enrichment screens. This is likely due to the strong enrichment of combinatorial gene phenotypes and the associated underrepresentation of single-gene effects. However, this can be compensated for by including a dedicated single gene screen when planning combinatorial enrichment screens. Furthermore, we note that genes associated with strong phenotypes are sufficiently identified by this approach, but genes causing milder phenotypes will likely miss attention. This obstacle, however, is circumvented by carefully examining gene-interactions in the class of phenotype-associated nonessential gene pairs. Indeed, we demonstrate that AMBRA1, ULK1, WIPI2, and BECN1 are essential for autophagy, even though both single gRNA screens failed to identify them.

355 Genome-wide or combinatorial CRISPR screens demand large numbers of cells. Thus, current 356 efforts aim at minimizing cell culture demands by providing combinatorial-gRNA minimized 357 CRISPR libraries ${ }^{59,62}$. Supporting this notion, we identify log2FC of dual-gRNA targeted genes to 358 be larger than their single-gRNA targeted counterpart. Interestingly, this observation was limited 359 to genes that we identified to be essential for autophagy, supporting the notion that dual-gRNA 
gene targeting also induces stronger phenotypes in enrichment screens and that minimized libraries will also be beneficial for these applications.

362 Functional buffering by paralogs has recently been shown to be largely absent from single gRNA CRISPR screens ${ }^{63}$, suggesting paralogs to contribute to network redundancy. Indeed, we identify paralogs as functional buffers in autophagy acting in autophagosome assembly (ATG2A/B), phosphatidylinositol phosphorylation (PIK3CA/PI4K2A), and phagosome-lysosome fusion (RAB7A/5A and RAB7B/5A). This is profoundly important when therapeutically targeting autophagy induction in cells that are dependent on high basal autophagy levels such as acute myeloid leukemia (AML) cells ${ }^{64}$. Lastly, we note that our analysis failed to identify functional buffering within the mammalian ATG8 family of proteins (LC3s and GABARAPs), as well as within the protein class of autophagy receptors (FUNDC1, SQSTM1, OPTN, PLEKHM1, PEX13, CALCOCO2, FAM134B). Furthermore, the lack of buffering gene interactions between ATG8s and autophagy receptor proteins, together, supports the notion of their cargo selectivity that prevents these genes to contribute to autophagy redundancy ${ }^{65}$.

\section{MATERIAL AND METHODS}

\section{Cs multiplex template plasmid DNA and cloning}

pLentiCRISPRv2 (Addgene: 98290) was enzymatically digested with Alel and BsiWl and gel purified to remove the hU6 gRNA- and SpCas9-expressing cassettes. Likewise, the combinatorial gRNA-expressing cassette of pKLV2.2 (Addgene: 72666) was digested with Alel and BsiWI. The 2030 bp fragment that encodes the combinatorial gRNA-expressing cassettes and a PGK promoter was gel purified and cloned into the reduced, purified backbone of pLentiCRISPRv2. In order to generate unique annealing homology for the $3 \mathrm{Cs}$ oligonucleotides and enable template plasmid removal, the h7SK promoter-associated tracrRNA was replaced by a previously engineered tracrRNA sequence (tracrRNA v2) and h7SK and hU6 promoter-associated gRNA cloning sites were modified to contain placeholder sequences encoding for I-Ceul and I-Scel homing endonuclease restriction sites, respectively ${ }^{66}$.

\section{Cs oligonucleotide design rules}

All oligonucleotides that were used for multiplexed 3Cs gRNA library generation are listed in 'DNA oligonucleotides'. DNA oligonucleotides were purchased from Sigma-Aldrich, from Integrated DNA Technologies (IDT) as single or pooled oligonucleotides in o-pool formats, and from Twist 
To discriminate between h7SK and hU6 and enable exclusive annealing to only one expression cassette, the $3 \mathrm{Cs}$ oligonucleotides were designed with two specific homology regions flanking the intended 20-nt gRNA sequence for either the h7SK or hU6 expression cassettes. The 3Cs h7SKoligonucleotides were $57 \mathrm{nts}$ in length $\left(\mathrm{Tm}\right.$ above $50^{\circ} \mathrm{C}$ ) and matched the $3^{\prime}$ end of the h7SK promoter region and the $5^{\prime}$ start of the tracrRNA v2, while the 3Cs hU6-oligonucleotides were 59 nts in length $\left(\mathrm{Tm}\right.$ above $\left.50^{\circ} \mathrm{C}\right)$ and matched the $3^{\prime}$ end of the hU6 promoter region and the $5^{\prime}$ start of the tracrRNA $v 1$ in the template plasmids.

\section{Generation of sequence distorted $3 \mathrm{Cs}$ libraries}

402 For the generation of biased multiplex 3Cs gRNA libraries, two 3Cs oligonucleotide pools were 403 designed for each expression cassette of the 3Cs multiplex template plasmid following the 3Cs 404 oligonucleotide design rules. The first pool was composed of tumor suppressor and essential 405 gene-targeting gRNAs (target pool), while the second pool only included non-human targeting 406 gRNAs (control pool). To generate three different libraries that represent libraries of different quality regarding their distribution, the two oligonucleotide pools were mixed in a different ratio for each of the three libraries. For the first library, the target and control pool were mixed in a 1:1 ratio, to resemble an evenly distributed gRNA library. For the second library a 1:10 ratio of target to control pool was applied. The third library was generated with a 1:100 ratio, to resemble a library with highly underrepresented gRNA sequences. The mixed oligonucleotide pools were phosphorylated, annealed to purified dU-ssDNA of the $3 \mathrm{Cs}$ multiplex template plasmid, and the $3 \mathrm{CS}$ synthesis reactions were performed as described above.

\section{Generation of multiplexed 3Cs- gRNA libraries}

417 Desktop microcentrifuge, shaking incubator at $37^{\circ} \mathrm{C}, 1.5 \mathrm{ml}$ collection tubes, filtered sterile pipette

418 tips, thermoblocks at $90^{\circ} \mathrm{C}$ and $50^{\circ} \mathrm{C}$ (e.g., Thermo Fisher, 88870004), an ultracentrifuge capable 419 of spinning $50 \mathrm{ml}$ falcon tubes at 10,000 rpm (Beckman Coulter Avanti J-30 I ultracentrifuge and 420 a Beckman JA-12 fixed angle rotor), falcon tubes (polypropylene, $50 \mathrm{ml}$ (Corning 352070)), a Bio-

421 Rad Gene Pulser electroporation system (BioRad 164-2076), electroporation cuvettes Plus (2 $422 \mathrm{~mm}$, Model no. 620 (BTX)), a gel electrophoresis chamber, erlenmeyer flasks (glass, $200 \mathrm{ml}$ and $423500 \mathrm{ml}$ ), $10 \mathrm{~cm}$ dishes $10 \mathrm{~cm}$ plastic culture dishes (Corning, CLS430591), $14 \mathrm{ml}$ round-bottom 424 polystyrene tubes (e.g. Thermo Fisher, 10568531). 
KCM transformation

$428 \mathrm{KCM}$ competent bacteria (Escherichia coli strain K12 CJ236, NEB, E4141) were transformed with $4293 \mathrm{Cs}$ multiplex template plasmid template by mixing $100 \mathrm{ng}$ of DNA with $2 \mu \mathrm{l}$ of $5 \mathrm{x}$ KCM buffer $430(0.5 \mathrm{M} \mathrm{KCl}, 0.15 \mathrm{M} \mathrm{CaCl} 2,0.25 \mathrm{M} \mathrm{MgCl} 2)$ and water in a $10 \mu \mathrm{l}$ reaction. After 10 min of incubation 431 on ice, an equal volume of CJ236 bacteria was added to the DNA/KCM mixture, gently mixed, 432 and chilled on ice for $15 \mathrm{~min}$. The bacteria-DNA mixture was then incubated at room temperature 433 for $10 \mathrm{~min}$ and subsequently inoculated into $200 \mu \mathrm{l}$ of prewarmed SOC media (ThermoFisher 434 Scientific, 15544034). Bacteria were incubated at $37^{\circ} \mathrm{C}$ and $200 \mathrm{rpm}$ for $1 \mathrm{hr}$ and then streaked 435 on LB-agar plates with ampicillin $(100 \mu \mathrm{g} / \mathrm{ml})$ and chloramphenicol $(34 \mu \mathrm{g} / \mathrm{ml})$ for incubation 436 overnight at $37^{\circ} \mathrm{C}$.

Phage amplification and ssDNA purification

439 The morning after transformation, a single colony of transformed E. coli CJ236 was picked into 1 $\mathrm{ml}$ of 2YT media (Roth, 6676.2) supplemented with M13KO7 helper phage (NEB, N0315) to a final concentration of $1 \times 10^{8} \mathrm{pfu} / \mathrm{ml}$ and ampicillin (final concentration $100 \mu \mathrm{g} / \mathrm{ml}$ ) to maintain the host $\mathrm{F}^{\prime}$ episome and the phagemid, respectively. After $2 \mathrm{hrs}$ of shaking at $200 \mathrm{rpm}$ and $37^{\circ} \mathrm{C}$, kanamycin (Roth, T832.3) was added to a final concentration of $25 \mu \mathrm{g} / \mathrm{ml}$ to select for bacteria 444 that have been infected with M13KO7 helper phage. Bacteria were kept at $200 \mathrm{rpm}$ and $37^{\circ} \mathrm{C}$ for 4456 to $8 \mathrm{hrs}$. Afterwards, the culture was transferred to $30 \mathrm{ml}$ of 2YT media supplemented with 446 ampicillin (final concentration $100 \mu \mathrm{g} / \mathrm{ml}$ ) and kanamycin (final concentration $25 \mu \mathrm{g} / \mathrm{ml}$ ). After an 447 additional $20 \mathrm{hrs}$ of shaking at $200 \mathrm{rpm}$ and $37^{\circ} \mathrm{C}$, the bacterial culture was centrifuged for $10 \mathrm{~min}$ 448 at $10,000 \mathrm{rpm}$ and $4^{\circ} \mathrm{C}$ in a Beckman JA-12 fixed angle rotor. The supernatant was subsequently 449 transferred to $6 \mathrm{ml}(1 / 5$ of culture volume) $\mathrm{PEG} / \mathrm{NaCl}(20 \%$ polyethylene glycol 8,000, $2.5 \mathrm{M} \mathrm{NaCl})$ 450 and incubated for $1 \mathrm{hr}$ at room temperature to precipitate phage particles. After $10 \mathrm{~min}$ of 451 centrifugation at $10,000 \mathrm{rpm}$ and $4^{\circ} \mathrm{C}$ in a Beckman JA-12 fixed angle rotor, the phage pellet was 452 resuspended in $1.5 \mathrm{ml}$ Dulbecco's phosphate-buffered saline (PBS, Sigma, D8662) and 453 centrifuged at 13,000 rpm for $5 \mathrm{~min}$, before the phage-containing supernatant was transferred to 454 a clean $1.5 \mathrm{ml}$ microcentrifuge tube and stored at $4^{\circ} \mathrm{C}$. Circular ssDNA was purified from the 455 resuspended phages with the E.Z.N.A. M13 DNA Mini Kit (Omega Bio-Tek, D69001-01) according 456 to the manufacturer's protocol. Purity of the isolated ssDNA was ensured by agarose gel 457 electrophoresis and purified ssDNA was stored at $4^{\circ} \mathrm{C}$. 
The protocol for multiplexed 3Cs-DNA synthesis was adapted from Wegner et al., 2019 and optimized for reactions on the 3Cs multiplex template plasmid with two specific annealing sites. The oligonucleotides that were used for $3 \mathrm{Cs}$ reactions and the suppliers are listed separately (see '3Cs oligonucleotide design rules' and 'DNA oligonucleotides').

\section{Oligonucleotide phosphorylation and annealing}

$466600 \mathrm{ng}$ of oligonucleotides per annealing site (both, 3Cs h7SK- and hU6-oligonucleotides) were 467 phosphorylated in two separate $20 \mu \mathrm{l}$ reactions by mixing them with $2 \mu \mathrm{l} 10 \mathrm{x}$ TM buffer $(0.1 \mathrm{M}$

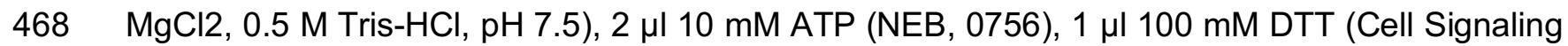
469 Technology Europe, 7016), 20 units of T4 polynucleotide kinase (NEB, M0201) and water to a 470 total volume of $20 \mu \mathrm{l}$. The mixture was incubated for $1 \mathrm{hr}$ at $37^{\circ} \mathrm{C}$. Phosphorylated oligonucleotides 471 were immediately annealed to purified multiplex dU-ssDNA template by adding both $20 \mu \mathrm{l}$ 472 phosphorylation products to $25 \mu \mathrm{l} 10 \mathrm{x}$ TM buffer, $20 \mu \mathrm{g}$ of dU-ssDNA template and water to a total 473 volume of $250 \mu \mathrm{l}$. The mixture was denatured for $5 \mathrm{~min}$ at $95^{\circ} \mathrm{C}$, annealed for $5 \mathrm{~min}$ at $55^{\circ} \mathrm{C}$ and cooled down for $10 \mathrm{~min}$ at room temperature.

\section{Multiplexed 3Cs-DNA reaction}

3Cs-DNA was generated by adding $10 \mu \mathrm{l}$ of $10 \mathrm{mM}$ ATP, $10 \mu \mathrm{l}$ of $100 \mathrm{mM}$ dNTP mix (Roth, synthesis mix was incubated for $12 \mathrm{hrs}$ (overnight) at room temperature. Afterwards the $3 \mathrm{Cs}$ synthesis product was purified and desalted using a GeneJET Gel Extraction Kit (Thermo Fisher, K0692) according to the following protocol: $600 \mu \mathrm{l}$ of binding buffer and $5 \mu \mathrm{l} 3 \mathrm{M}$ sodium acetate columns, which were centrifuged for $3 \mathrm{~min}$ at $460 \mathrm{~g}$. The flow-through was applied a second time to the same purification column to maximize yield. After two wash steps and 3 min of centrifugation at maximum speed, the DNA was eluted in $50 \mu$ prewarmed water. The $3 \mathrm{Cs}$ reaction product was analyzed by gel electrophoresis alongside the dU-ssDNA template on a $0.8 \%$ TAE/agarose gel (100 V, $30 \mathrm{~min})$.

\section{Multiplexed 3Cs-DNA library amplification, clean-up and quality control}

491 Electroporation of 3Cs synthesis product

492 To amplify the multiplex 3Cs libraries, the 3Cs-DNA synthesis product was electroporated. To do 493 so, $400 \mu \mathrm{l}$ of electrocompetent E. coli (10-beta, NEB, C3020K) were thawed on ice and mixed 
with $6 \mu \mathrm{g}$ of purified 3Cs-DNA. For electroporation, the DNA must be eluted in water or a low salt solution. After that, the mixture was incubated on ice for 15 min and then transferred into a cold $2 \mathrm{~mm}$ cuvette (BTX, 45-0125) that was then inserted into a Bio-Rad Gene Pulser with the following settings: resistance $200 \Omega$, capacity $25 \mathrm{~F}$, voltage $2.5 \mathrm{kV}$. After electroporation, cells were rescued in $25 \mathrm{ml}$ of pre-warmed SOC media and incubated for $30 \mathrm{~min}$ at $37^{\circ} \mathrm{C}$ and $200 \mathrm{rpm}$. After $30 \mathrm{~min}$ the culture was transferred into $400 \mathrm{ml}$ of LB media supplemented with $100 \mu \mathrm{g} / \mathrm{ml}$ 500 ampicillin.

\section{Determination of transformation efficiency}

503 To ensure library representation during and after amplification, the number of transformants was 504 determined. After $30 \mathrm{~min}$ of incubation at $37^{\circ} \mathrm{C}$ and $200 \mathrm{rpm}$ subsequently to the electroporation, 505 a series of 10 -fold dilutions of the $10 \mu \mathrm{l}$ of bacterial culture in sterile Dulbecco's phosphate506 buffered saline (PBS, Sigma, D8662) was prepared. Dilutions were plated in triplicates on LBagar containing $100 \mu \mathrm{g} / \mathrm{ml}$ ampicillin and incubated overnight at $37^{\circ} \mathrm{C}$. The next morning, the obtained colonies were counted. The number of transformants must be at least 100 -fold higher than the library complexity to ensure maintenance of library diversity.

I-Ceul and I-Scel clean-up and quality control

512 Plasmid DNA of overnight liquid cultures was purified using the Qiagen Plasmid Maxi Kit (Qiagen, 513 12163), according to the manufacturer's protocol to obtain the pre-library (P1). For removal of 514 residual $3 \mathrm{Cs}$ template plasmid from the multiplex pre-library, $3 \mu \mathrm{g}$ of purified DNA was digested 515 with 10 units I-Scel (NEB, R0694), 10 units I-Ceul (NEB, R0699) and $5 \mu$ I NEB CutSmart buffer 516 (NEB, B7204) in a reaction volume of $50 \mu \mathrm{l}$ for $3 \mathrm{hrs}$ at $37^{\circ} \mathrm{C}$. After $3 \mathrm{hrs}$, an additional 10 units of 517 I-Scel and I-Ceul and $5 \mu$ I NEB CutSmart buffer were added, as well as water to a final volume 518 of $100 \mu \mathrm{l}$. After further incubation for additional 3 hours, the digestion reaction was subjected to 519 gel electrophoresis on a $0.8 \%$ TAE/agarose gel $(125 \mathrm{~V}, 40 \mathrm{~min})$ to separate undigested 3Cs 520 synthesis product from linearized template plasmid. The band resembling the undigested correct 5213 Cs synthesis product was purified using a Thermo Fisher Scientific GeneJET Gel Extraction Kit, 522 according to the manufacturer's protocol. Then, the purified 3Cs synthesis product was 523 electroporated, according to the electroporation protocol described above. The next day, the 524 resulting final 3Cs multiplex library preparation (P2) was purified from liquid culture using a Qiagen 525 Plasmid Maxi Kit, according to the manufacturer's protocol and quality controlled by analytical 526 restriction enzyme digests, SANGER sequencing and by Next Generation Sequencing. 


\section{Next-generation sequencing (NGS)}

NGS sample preparation of 3Cs multiplex plasmid libraries

530 3Cs multiplex plasmid libraries were prepared for NGS as follows: 250 ng of plasmid DNA was 531 used per PCR reaction and used in a volume of $50 \mu \mathrm{l}$ using Next High-Fidelity 2x PCR Master $532 \operatorname{Mix}$ (NEB, M0541) (according to the manufacturer's protocol), containing $2.5 \mu \mathrm{l}$ of $10 \mu \mathrm{M}$ primers

533 each of forward and reverse primers. Depending on the library complexity up to four $50 \mu \mathrm{l}$ 534 reactions were performed. Primer sequences are listed separately (see 'DNA oligonucleotides').

535 Thermal cycler parameters were set as follows: initial denaturation at $98^{\circ} \mathrm{C}$ for 5 min, 15 cycles of 536 denaturation at $98^{\circ} \mathrm{C}$ for $30 \mathrm{~s}$, annealing at $65^{\circ} \mathrm{C}$ for $30 \mathrm{~s}$, extension at $72^{\circ} \mathrm{C}$ for $40 \mathrm{~s}$, and final 537 extension at $72^{\circ} \mathrm{C}$ for $5 \mathrm{~min}$. PCR products were purified from a $1.5 \%$ TAE/agarose gel using a 538 GeneJet Gel Extraction Kit (Thermo Fisher Scientific), according to manufacturer's protocol. 539 Purified PCR products were denatured and diluted according to Illumina the guide lines and set to a final concentration of $2.6 \mathrm{pM}$ in a total volume of $2.2 \mathrm{ml}$ and $15 \%$ PhiX control and loaded onto a MiSeq, NextSeq 500 or NovaSeq sequencer (Illumina), according to manufacturer's protocol. Sequencing was performed with single- or paired-end reads, 75 or 150 cycles, plus 8 cycles of index reading.

NGS sample preparation of 3Cs multiplex screening samples

546 To prepare 3Cs multiplex screening samples, the required amount of genomic DNA for sufficient 547 coverage was calculated first: for the autophagy single and multiplex FACS screening samples, 548 the required genomic DNA was calculated as number of FACS sorted cells $\times$ 549 screening coverage $x 6.6 \mathrm{pg}$. For the autophagy multiplex proliferation control screen, the 550 required genomic DNA was determined by calculating librarycomplexity $\times$ 551 screening coverage $x 6.6 \mathrm{pg}$.

552 The NGS sample preparation of all samples from screening with the biased libraries was 553 performed with library complexity $\times 200$ (maximum screening coverage) $x 6.6 p g$ DNA. The 554 calculated amount of genomic DNA was used in a first PCR (PCR1) reaction with 2 to $4 \mu \mathrm{g}$ of 555 genomic DNA in a $50 \mu \mathrm{l}$ reaction using the Next High-Fidelity 2x PCR Master Mix (NEB, M0541) 556 (according to the manufacturer's protocol) and $2.5 \mu \mathrm{l}$ of $10 \mu \mathrm{M}$ PCR1 primers, each of forward 557 and reverse. Thermal cycler parameters were set as follows: initial denaturation at $98^{\circ} \mathrm{C}$ for 5 min, 55815 cycles of denaturation at $98^{\circ} \mathrm{C}$ for $55 \mathrm{~s}$, annealing at $65^{\circ} \mathrm{C}$ for $55 \mathrm{~s}$, extension at $72^{\circ} \mathrm{C}$ for 110 $559 \mathrm{~s}$, and final extension at $72^{\circ} \mathrm{C}$ for $7 \mathrm{~min}$. After PCR 1, $25 \mu \mathrm{l}$ of PCR 1 product was transferred to 560 a second PCR reaction (PCR2) in a $100 \mu$ reaction with $50 \mu$ High-Fidelity 2x PCR Master Mix 561 and $2.5 \mu$ l of $10 \mu \mathrm{M}$ PCR 2 primers that contain Illumina adaptors. Primer sequences for PCR1 
and PCR2 are listed separately (see 'DNA oligonucleotides'). Thermal cycler parameters were set as follows: initial denaturation at $98^{\circ} \mathrm{C}$ for $5 \mathrm{~min}, 10$ cycles of denaturation at $98^{\circ} \mathrm{C}$ for $30 \mathrm{~s}$, annealing at $65^{\circ} \mathrm{C}$ for $30 \mathrm{~s}$, extension at $72^{\circ} \mathrm{C}$ for $40 \mathrm{~s}$, and final extension at $72^{\circ} \mathrm{C}$ for $5 \mathrm{~min}$. PCR products were purified from a $1.5 \%$ TAE/agarose gel and processed for NGS sequencing as described for plasmid libraries.

\section{NGS data quality control and read count table generation}

569 Raw next generation sequencing data were processed and demultiplexed with bcl2fastq 570 v2.19.1.403 (Illumina). Read counts of individual gRNAs and gRNA combinations were 571 determined using cutadapt 2.8, Bowtie2 2.3.0, and custom Python 3 scripts $^{67,68}$. In brief, reads 572 were trimmed with cutadapt using 5' adapter sequences, truncated to 20 nucleotides, and aligned

573 to the respective gRNA library using Bowtie2 with no mismatches allowed. The uniformity of each 574 library distribution was assessed by plotting the cumulative distribution of all sequencing reads as 575 a Lorenz curve and determining the area under the curve. The library distribution skew (skew 576 ratio) of each library was determined by plotting the density of read counts and dividing the top 57710 quantiles by the bottom 10 quantile. Cohen's $D$ statistics were applied to assess the quality of 578 the biased libraries by comparing the distributions of non-targeting sequences and sequences 579 targeting core essential genes ${ }^{52}$. Pairwise sample correlations were determined with Pearson's 580 correlation of the normalized read counts and visualized with hierarchically clustered heat maps 581 (Seaborn library 0.10.1 $)^{69}$.

584 All enrichment analyses using MAGeCK were performed with median normalization of read 585 counts and gRNAs with zero counts in the control samples were removed. Down-sampling of the $5861: 1$ dataset was performed by randomly choosing 1 to 16 gRNA combinations per gene 587 combination without replacement followed by individual MAGeCK analyses. gRNA combinations 588 with an $\mathrm{FDR} \leq 10 \%$ and $\log 2 \mathrm{FC} \leq-0.5$ were counted as statistically significant hits.

\section{Genetic interaction models}

591 Interactions of gene pairs were computed according to five different models: SUM, MIN, LOG, 592 MULT were used according to their definition in $^{17}$, the MAX model defines the expected phenotype 593 of a double gene-knockout as the maximal phenotype of the individual single gene-knockouts. 594 The expected phenotypes of all double gene-knockouts were computed based on the phenotype 595 of the respective single gene knockouts which were defined as the median log2FC (as provided 
by the MAGeCK analysis output) of all combinations of NHTs and gRNAs targeting the respective gene. For each model, the deviation of observed paired-knockout phenotypes from their expectation were expressed as their difference: $\triangle \log 2 F C=$ observed - expected. Assuming that genetic interactions were rare, density plots of the dLFCs for each model were used to identify the model with the highest number of neutral interactions, indicated by a single large peak around

6010 on the $\mathrm{x}$-axis. Using the MAX model, we kept only combinations with $\mathrm{p} \leq 0.05$ and a $\triangle \log 2 \mathrm{FC}$ 602 larger than the standard deviation of all $\Delta \log 2 \mathrm{FCs}$.

\section{Autophagy gene interaction network}

605 To generate a network visualization based on our derived gene-gene interactions in autophagy, we exported MAX model-dependent delta log2FC per gene-gene interaction and imported them into the open source software platform for visualizing complex networks, Cytoscape $(3.8 .0)^{70}$. The style of the derived network was manually curated with the layout being set to a circular one.

\section{Cell culture}

Cell culture was performed as described previously ${ }^{45}$. In brief, HEK293T cells (ATCC, CRL-3216) were maintained in Dulbecco's Modified Eagle's Medium (DMEM, Thermo Fisher Scientific, 41965-039) and puromycin-sensitive hTERT-RPE1 cells (provided by Andrew Holland) in DMEM: Nutrient Mixture F-12 (DMEM/F12, Thermo Fisher Scientific, 11320-074), each supplemented with $10 \%$ fetal bovine serum (FBS, Thermo Fisher Scientific, 10270) and 1\% penicillin-streptomycin (Sigma-Aldrich, P4333) at $37^{\circ} \mathrm{C}$ with $5 \% \mathrm{CO} 2$. In addition, hTERT-RPE1 cells were supplemented with $0.01 \mathrm{mg} / \mathrm{ml}$ hygromycin B (Capricorn Scientific, HYG-H). No method to ensure the state of authentication has been applied. Mycoplasma contamination testing was performed immediately after the arrival of the cells and multiple times during the course of the experiments. The hTERT-RPE1 GFP-LC3-RFP reporter cell line was generated by transducing hTERT-RPE1(Cas9) cells with retroviral particles generated with the transfer plasmid pMRX-IP-GFP-LC3-RFP (Addgene: 84573). Single cell clones were isolated and reporter functionality was tested by Torin 1 and Bafilomycin $A 1$ treatments.

\section{Genomic DNA extraction}

626 Genomic DNA of cells was purified by resuspending PBS washed pellets of 40-50 million cells in $62712 \mathrm{ml}$ of TEX buffer (10 mM Tris- $\mathrm{HCl}$, ph 7.5, $1 \mathrm{mM}$ EDTA, ph 7.9, 0.5\% SDS). Then $300 \mu \mathrm{l}$ of 628 proteinase $\mathrm{K}(10 \mathrm{mg} / \mathrm{m})$ and $300 \mu \mathrm{l}$ of Ribonuclease $\mathrm{A}(90 \mathrm{U} / \mathrm{mg}, 20 \mathrm{mg} / \mathrm{ml})$ were added to the 629 resuspended cells. The tubes were incubated overnight at $37^{\circ} \mathrm{C}$ at constant shaking. After 
630 complete cell lysis, $4 \mathrm{ml}$ of $5 \mathrm{M} \mathrm{NaCl}$ was added, the solution was mixed and incubated at $4{ }^{\circ} \mathrm{C}$

631 for $40 \mathrm{~min}$. After that the tubes were centrifuged at 14,000xg for $1 \mathrm{hr}$. The supernatant was

632 transferred to a fresh tube and $24 \mathrm{ml}$ of ice-cold $96 \%$ ethanol was added before the mixture was

633 placed at $-20^{\circ} \mathrm{C}$ overnight. The next day, the tubes were centrifuged at $14,000 x g$ for $1 \mathrm{hr}$.

634 Afterwards the supernatant was removed and the precipitated DNA was washed with ice-cold

$63570 \%$ ethanol. After further centrifugation 14,000xg for $1 \mathrm{hr}$ the supernatant was removed and the

636 DNA pellet was dried at room temperature and then dissolved in $5 \mathrm{ml}$ of sterile water.

\section{GFP and mCherry knockouts}

639 To examine the expression of gRNAs from both expression cassettes of the 3Cs multiplex 640 template plasmid, two oligonucleotide pools were designed following the 3 Cs oligonucleotide 641 design rules. One oligonucleotide pool was designed for the h7SK cassette with 50 gRNAs 642 targeting eGFP, the second pool was designed for the hU6 expression cassette with 50 gRNA 643 targeting the mCherry gene. The two pools were used to generate three $3 \mathrm{Cs}$ libraries to selectively 644 target either eGFP (GFP single library) or mCherry (mCherry single library) or both simultaneously 645 (eGFP-mCherry multiplex library) following the protocol for generation of multiplexed 3Cs-gRNA 646 libraries described above. Lentiviral supernatant of the three libraries was generated. Monoclonal 647 hTERT-RPE1 cells with stable SpCas9, eGFP and mCherry expression were plated at $40 \%$ 648 confluency. The next day, the cells were transduced with viral supernatant of one of the three 649 libraries. After $48 \mathrm{hrs}$ of transduction, cells were selected with puromycin $(2.5 \mu \mathrm{M})$ for 10 days. 650 Then, eGFP and mCherry ratios were quantified by FACS analysis.

653 Generation, quantification and transduction of lentiviral particles was performed as described 654 previously ${ }^{45}$. In brief, the day before transfection, HEK293T cells were seeded to $2.5 \times 10^{5}$ 655 cells/ml. To transfect HEK293T cells, transfection media containing 1/10 of culture volume Opti656 MEM I (Thermo Fisher Scientific, 31985-047), $10.5 \mu \mathrm{l}$ Lipofectamin 2000 (Thermo Fisher 657 Scientific, 11668019), $1.65 \mu \mathrm{g} / \mathrm{ml}$ transfer vector, $1.35 \mu \mathrm{g} / \mathrm{ml}$ pPAX2 (Addgene: 12260) and 0.5/ml $658 \mu \mathrm{g}$ pMD2.G (Addgene: 12259) was prepared. The mixture was incubated for $30 \mathrm{~min}$ at room 659 temperature and added dropwise to the media. Lentiviral supernatant was harvested $48 \mathrm{hr}$ after 660 transfection and stored at $-80^{\circ} \mathrm{C}$.

661 To determine the lentiviral titer, hTERT-RPE1 cells were plated in a 6-well plate with 50,000 cells 662 per well. The following day, cells were transduced in the presence of $8 \mu \mathrm{g} / \mathrm{ml}$ polybrene (Sigma, 
$\mathrm{H} 9268$ ) and a series of $0.5,1,5$, and $10 \mu$ l of viral supernatant. After 2 days of incubation at $37^{\circ} \mathrm{C}$, cells were subjected to puromycin selection for a total duration of 2 weeks, after which established colonies were counted per viral dilution. The number of colonies in the highest dilution was then volume normalized to obtain the final lentiviral titer.

667 To transduce hTERT-RPE1 cells, they were seeded at an appropriate density for each 668 experiment with a maximal confluency of $60-70 \%$. On the day of transduction, polybrene was 669 added to the media to a final concentration of $8 \mu \mathrm{g} / \mathrm{ml}$. The volume of lentiviral supernatant was 670 calculated on the basis of the diversity of the respective library and of the desired coverage and 671 multiplicity of infection (MOI) of the experiment. A MOI of 0.5 was applied to all screens. The 672 number of cells that were transduced at the beginning of an experiment was calculated by 673 multiplying the diversity of the library with the desired coverage and needed MOI.

\section{Cs CRISPR screening}

676 Library distribution and experimental coverage interdependency screening

677 To explore the interdependency of multiplexed CRISPR library distribution and experimental 678 screening coverage, three distorted 3Cs multiplex libraries were generated (see 'generation of distorted libraries') that represented libraries of different gRNA distributions. All three libraries were screened with a 20 -fold and 200 -fold coverage, each in triplicates. For the 20 -fold screening, for each replicate, 1.1 million SpCas9 expressing hTERT-RPE1 cells were plated (0.37 million cells per flask) and transduced with the respective library with a $\mathrm{MOI}$ of 0.5 . After $48 \mathrm{hrs}$ the cells were selected with $2 \mu \mathrm{M}$ puromycin and kept in growing conditions for 14 days. At day 14 , the cells were harvested, pooled and stored at $-20^{\circ} \mathrm{C}$ until their genomic DNA was extracted and processed for NGS. For the 200-fold screening a total of 11 million ( 0.5 million cells per flask) SpCas9 expressing hTERT-RPE1 cells were plated and transduced with the respective library with a $\mathrm{MOI}$ of 0.5 . Further screening was performed identically to the 20 -fold screen.

690 Autophagy single and combinatorial gRNA screens for single or synergistic autophagy inhibition 691 were performed in biological replicates and triplicates in the monoclonal hTERT-RPE1 cell line 692 that stably expresses Streptococcus pyogenes Cas9 (SpCas9) and the autophagic flux probe 693 (GFP-LC3-RFP) ${ }^{56}$, respectively. For each replicate 20 million cells (10 million for each, end time 694 point and day 2 control) were transduced with lentiviral supernatant of the autophagy multiplex 695 library with an $\mathrm{MOI}$ of 0.5 and a 1000 - or 20-fold library coverage for single or combinatorial 696 autophagy library screening, respectively. The control time points were harvested 2 days post- 
697 transduction. All remaining cells were kept in growing conditions until day 7 , at what pint the cells

698 were passaged, pooled and reseeded at library-diversity-maintaining density. After 13, 14 and 15

699 days the cells were treated with the mTOR inhibitor Torin1 (250 nM, InvivoGen, 1222998-36-8)

700 for $24 \mathrm{hrs}$ in three batches to induce autophagy. After $24 \mathrm{hrs}$ of Torin1 treatment, cells were

701 collected and 50,000 to 100,000 cells for single or 1.5 to 2.25 million cells for combinatorial

702 screening of each batch were FACS sorted to enrich for cells with blocked autophagy. The sorted

703 cells were reseeded and expanded for seven days before they were harvested, pooled and stored

704 at $-20^{\circ} \mathrm{C}$ until their genomic DNA was extracted and processed for NGS.

\section{FACS}

707 Cell sorting was carried out with the FACS core facility of the Georg-Speyer Haus on a BD 708 FACSAria Fusion, and CRISPR screening hit validation analysis on a FACSCanto II flow cytometer (BD Biosciences). Data was processed by FlowJo (FlowJo, LLC). Gating was carried out on the basis of viable and single cells that were identified on the basis of their scatter morphology.

\section{Arrayed autophagy candidate validation}

714 The validation of single and combinatorial autophagy screening hits was performed in arrayed conditions (one knockout per well). To do so, single and dual gene-targeting CRISPR constructs were designed and generated. For each gene, the top scoring guide sequence was selected with Azimuth 2.0 of the GPP sgRNA Designer (https://portals.broadinstitute.org/gpp/public/analysistools/sgrna-design) and purchased as forward and reverse oligonucleotide with compatible overhangs for restriction enzyme cloning (see 'DNA oligonucleotides'). The two oligonucleotides containing the gRNA target site were annealed and cloned into a restriction-enzyme digested and gel purified CRISPR vector. In more detail, single gRNA constructs were cloned into lenti-sgRNA blast vector (Addgene: 104993) by BsmBI restriction enzyme cloning. For combinatorial hit

723 validation the dual CRISPR gRNA expression cassettes of pKLV2.2-h7SKgRNA5(Sapl)724 hU6gRNA5(Bbsl)-PGKpuroBFP-W (Addgene: 72666) was cloned into the lenti-sgRNA blast 725 plasmid to enable blasticidin selection of dual gRNA constructs. A silent point-mutation was 726 introduced to remove the Bbsl recognition site within the blasticidin sequence to allow the 727 subsequent insertion of one gRNA by Sapl (NEB, R0569) cloning into the h7SK expression 728 cassette and the second gRNA by Bbsl (NEB, R0539) cloning into the hU6 expression cassette. 729 After cloning and sequence verification by SANGER sequencing, lentiviral supernatant was 730 generated for each construct as described. Monoclonal hTERT-RPE1 cells with stable SpCas9 
731 and GFP-LC3-RFP reporter expression were plated in 6-well plates with 50,000 cells per well.

732 The following day, cells were transduced in the presence of $8 \mu \mathrm{g} / \mathrm{ml}$ polybrene (Sigma, H9268)

733 with lentiviral supernatant. After $48 \mathrm{hrs}$ the cells were selected with $10 \mu \mathrm{g} / \mathrm{ml}$ blasticidin

734 (InvivoGen, ant-bl) for 7 days, passaged and cultivated at 40-60\% confluency under constant

735 blasticidin selection for an additional 7 days. At day 14, cells were treated with Torin1 to induce

736 autophagy for $24 \mathrm{hrs}$ until they were collected at day 15 and subject to FACS cell sorting to

737 measure single or dual gene-knockout-induced autophagy blockage.

gRNA performance and TIDE assay

740 Guide RNA performance was evaluated by TIDE assay, as described previously ${ }^{45,71}$. In short, for 741 each gRNA sequence, +/- 400 nucleotides from the gRNA annealing site, PCR primers were 742 designed to result in a PCR product of 800 to $1000 \mathrm{nts}$ in length. The gRNA-locus is then PCR 743 amplified with OneTaq DNA polymerase (NEB, M0480) using $1 \mu \mathrm{g}$ of genomic DNA, $40 \mu \mathrm{M}$ dNTPs 744 (final concentration), $0.2 \mu \mathrm{M}$ of each forward and reverse amplification primer, 10x OneTaq 745 standard buffer, and 2.5 units of OneTaq DNA polymerase. PCR cycles were set up as follows: 746 initial denaturation at $94^{\circ} \mathrm{C}$ for $3 \mathrm{~min}, 39$ cycles of denaturation at $94^{\circ} \mathrm{C}$ for $20 \mathrm{~s}$, annealing at $55^{\circ} \mathrm{C}$ 747 for $30 \mathrm{~s}$, strand extension at $68^{\circ} \mathrm{C}$ for $2 \mathrm{~min}$, and final strand extension at $68^{\circ} \mathrm{C}$ for $5 \mathrm{~min}$. The 748 PCR products were analyzed on a $0.8 \%$ TAE/agarose gel (100 V, $30 \mathrm{~min})$ and purified using a 749 Thermo Fisher Scientific GeneJET Gel Extraction Kit according to the manufacturer's protocol. 750 The purified PCR product was pre-mixed with forward amplification primer and processed by 751 SANGER sequencing, after which wildtype and gRNA-treated SANGER chromatograms were 752 analyzed by TIDE and the percentage of unedited DNA extracted (https://tide.deskgen.com/).

\section{Data availability}

755 NGS data are provided as raw read count tables as Supplementary Table 4. Plasmids encoding 756 for extended- and combinatorial-autophagy libraries will be available through the Goethe 757 University Depository (http://www.innovectis.de/INNOVECTIS-

758 Frankfurt/Technologieangebote/Depository).

\section{Code availability}

761 Custom software is publicly available from GitHuB, https://github.com/GEG-IBC2/3Cs-MPX 762 (GEG-IBC2, 2019; copy archived at https://github.com/elifesciences-publications/3Cs). 
Sequences of used DNA oligonucleotides and for 3Cs libraries are provided in Supplementary Table 2.

\section{FUNDING}

Hessisches Ministerium für Wissenschaft und Kunst (IIIL5-518/17.004)

771 Deutsche Forschungsgemeinschaft (EXC115/2)

772 Deutsche Forschungsgemeinschaft (EXC147/2)

773 Deutsche Forschungsgemeinschaft (EXC 2026)

Funders had no role in study design, data collection and interpretation, or the decision to submit 776 the work for publication.

\section{ACKNOWLEDGEMENTS}

We thank Andreas Ernst and Svenja Wiechmann for technical advice, Andrea Ballabio and

780 Davide Cacchiarelli of the Telethon Institute of Genetics and Medicine, as well as Sebastian

781 Wagner and Khalil Abou Elardat of the Cancer Genomics Core Facility Frankfurt, plus Tobias

782 Schmidt of the Institute of Biochemistry I (Pathobiochemistry) for valuable support with NGS. This

783 work was supported by the Hessian Ministry for Science and the Arts (HMWK, LOEWE-CGT, 784 IIIL5-518/17.004), the German Research Foundation (DFG; CEF-MC - EXC115/2; ECCPS 785 EXC147/2; CPI - EXC 2026) and in part by the LOEWE Center Frankfurt Cancer Institute (FCI) 786 funded by the Hessen State Ministry for Higher Education, Research and the Arts (IIIL5787 519/03/03.001-0015).

\section{COMPETING INTERESTS}

790 The Goethe University Frankfurt has filed a patent application related to this work on which 791 Valentina Diehl, Martin Wegner, Ivan Dikic and Manuel Kaulich are inventors (WO2017EP84625). 792 The Goethe University provides an exclusive license of the 3Cs technology to Vivlion $\mathrm{GmbH}$ for 793 which Ivan Dikic and Manuel Kaulich are co-founders, shareholders and chief officers.

\section{FIGURE LEGENDS}

796 Figure 1. 3Cs multiplexing for combinatorial CRISPR gRNA libraries. A) 3Cs 797 multiplexing workflow. Two gRNA-encoding oligonucleotide pools are selectively 
annealed to one of the gRNA-expression cassettes of the dU-containing ssDNA template plasmid for T7 DNA Pol-dependent generation of heteroduplex dU-dsDNA. Amplification in dut/ung-positive bacteria amplifies the combinatorial gRNA plasmid. See Material and Methods for a more details. B) Cas9 GFP/mCherry multiplex library design. Combinatorial gRNA constructs target GFP and mCherry genes simultaneously; each gene is individually targeted by 50 gRNAs, both genes are simultaneously targeted with 2601 gRNA combinations. The single guide GFP-targeting library contains the wildtype gRNA placeholder in the hU6 cassette (mCherry), and vice versa. C) Gel-electrophoresis after analytical restriction enzyme digest of final 3Cs single and combinatorial libraries. D) Area-under-the-curve (AUC) determination of single and combinatorial library representation. As a reference, a perfectly distributed library (ideal) is shown in grey. Percentages indicate a library's representation at $90 \%$ of cumulative reads. AUC values are indicated next to each library's identifier. E) FACS analysis of GFP- and mCherrypositive hTERT-RPE1 cells after transduction with single or combinatorial libraries. Error bars represent standard deviations (SDs) over three biological replicates $(n=3)$.

Figure 2. Library distribution skew dictates experimental scale and data quality. A) Area-under-the-curve (AUC) determination of the nucleotide-randomized libraries. As a reference, a perfectly distributed library (ideal) is shown in grey. Percentages indicate

817 library representations at $90 \%$ of cumulative reads. AUC values are indicated next to each 818 library's identifier. B) Analysis of NHT-fraction in the biased 3Cs libraries. Median and 819 quartiles of the distributions are shown as red straight and black dotted line, respectively.

820 C) Area-under-the-curve (AUC) determination of the biased libraries. As a reference, a 821 perfectly distributed library (ideal) is shown in grey. Percentages indicate a library's 822 representation at $90 \%$ of cumulative reads. AUC values are indicated next to each 823 library's identifier. D) Density plots showing the log2FC separation of combinatorial gRNA 824 constructs targeting core essential genes (blue) and non-essential controls (green) in 825 experimental coverages of 20x (dotted) and 200x (straight). QS: quality score. E) Analysis 826 of the number of depleted gene-pairs detected with MAGeCK at the indicated FDR and $827 \log 2$ FC cutoffs. F) Determination of the number of depleted gene-pairs at the indicated 
828 FDR and log2FC cutoffs from sub-sampled read-count tables of replicates for each coverage containing 1 to 16 randomly chosen gRNA pairs.

Figure 3. Single and multiplex-inherent single gRNA enrichment screens are complementary. A) Cas9 autophagy single and multiplex library design. Combinatorial gRNA constructs target extended and core autophagy genes; each gene is targeted by 4 gRNAs, 192 extended autophagy genes and 64 core autophagy genes with $10 \%$ of NHT controls per cassette generating 247,032 gRNA combinations. Single gRNA extended autophagy library contains the wildtype gRNA placeholder in the hU6 cassette (core autophagy). B) Single (s) and combinatorial (mpx) autophagy screening workflow. Cov.: coverage (library representation); MOI: multiplicity of infection; FACS: fluorescenceactivated cell sorting; NGS: next-generation sequencing. C) Cell sorting representations of single and combinatorial (MPX) screen of post-FACS gate (\#) and high-gate $\left({ }^{*}\right)$. D) MAGeCK analysis of dedicated single gRNA autophagy screen of pre- and post-FACS samples with hit genes in red when matching cutoff criteria of FDR $\leq 10 \%$ and $p$ value $\leq 0.05$. Screen-selective hits in blue. E) MAGeCK analysis of multiplex-inherent single gRNA autophagy screen of pre- and post-FACS samples with hit genes in red when matching cutoff criteria of FDR $\leq 10 \%$ and $p$-value $\leq 0.05$. Screen-selective hits in blue. F) Analysis of single hit genes derived from D) and E) in arrayed autophagy blockage validations (red). Evaluation of gRNA activity by TIDE analysis (grey). Error bars represent standard error of mean (SEM) over three biological replicates per autophagy blockage $(n=3)$. ND: not determined.

Figure 4. Paralogs are redundant in autophagy. A) MAGeCK analysis of combinatorial gRNAs targeting gene pairs in which both genes were identified as essential for autophagy of pre- and post-FACS samples. Hit gene pairs are shown in red when matching cutoff criteria of $p$-value $\leq 0.05$. B) MAGeCK analysis of combinatorial gRNAs targeting gene pairs in which one gene was identified as essential for autophagy of preand post-FACS samples. Hit gene pairs are shown in blue when matching cutoff criteria

857 of p-value $\leq 0.05$. C) MAGeCK analysis of combinatorial gRNAs targeting gene pairs with 
859 Hit gene pairs are shown in yellow when matching cutoff criteria of $p$-value $\leq 0.05$. Ras860 related protein family (RAB) and ATG2 gene pairs are shown in blue and green, respectively. D) Global view on identified gene pairs per category in percent. Ess: essential; non-ess: non-essential. Color code adapted from A) to C). E-G) Arrayed analysis of hit gene pairs and the induced blockage of autophagy per gene knockout of each category, color code of A) to C). Control genes and sequences are shown in grey. Error bars represent standard error of mean (SEM) over three biological replicates $(n=3)$. H) Density plots of delta log2FC ( $\triangle \log 2 \mathrm{FC})$ analyses computed by MAX, SUM, MIN, MULT, and LOG models. I) Correlation between observed and expected log2FC values, derived from MAX model, for combinatorial gene-targeting. Data points above standard deviation and with $p$-values $\leq 0.05$, derived from $\mathrm{C}$ ), are highlighted in yellow, representing synergistic gene interactions in autophagy. J) Network analysis of synergistic autophagy gene pairs, derived form I). Edge color and width set to $\triangle \log 2 \mathrm{FC}$ values derived from MAX model. Edges and nodes of paralog gene pairs are highlighted in pink.

Supp. Figure 1. A) Analysis of single and multiplex dU-containing hetero-duplex 3Cs DNA by gel-electrophoresis. B) NGS sequencing depth of single and combinatorial GFP, mCherry, and GFP+mCherry 3Cs libraries. A sample's median and quartiles are shown as red straight and black dotted line, respectively. C) Analysis of distribution skew (skew) and completeness (compl.) per library, based on read counts derived from B).

Supp. Figure 2. A) NGS sequencing depth of nucleotide-randomized combinatorial 3Cs libraries (1-4N). A library's median and quartiles are shown as red straight and black dotted line, respectively. B) Analysis of distribution skew (skew) and completeness (compl.) per library, based on read counts derived from A). C) NGS sequencing depth of distribution skew biased combinatorial 3 Cs libraries (1:1, 1:10, 1:100). A sample's median and quartiles are shown as red straight and black dotted line, respectively. D) Analysis of distribution skew (skew) and completeness (compl.) per library, based on read counts 887 derived from $\mathrm{C}$ ). 
889 Supp. Figure 3. A-B) Pairwise sample correlation (Pearson's correlation coefficient), 890 visualized as hierarchically clustered heatmaps $(n)$, library distributions skews (1:1, 1:10, 891 1:100) and coverages (20x, 200x) on gRNA-pair (A) and gene-pair (B) levels. Color code 892 based on Pearson's correlation coefficient (rho) of normalized gRNA read counts.

Supp. Figure 4. A) FACS analysis of monoclonal hTERT-RPE1 GFP-LC3B-RFP reporter cell line under conditions of basal autophagy (Basal), Torin1-induced autophagy (+Torin1), and Torin1-induced but Bafilomycin A1-blocked autophagy (+Torin1 + Bafilomycin A1). Gating is based on Torin1-induced reduction of GFP signal; percentage (\%) of cells in gate. B) Analysis of NGS sequencing depth per 3Cs library (single, mpx) and replicate post-FACS sample (1-3). A sample's median and quartiles are shown as red straight and black dotted line, respectively. C) Analysis of distribution skew (skew) and completeness (compl.) per autophagy library (single, $\mathrm{mpx}$ ), based on read counts derived from B). D) Area-under-the-curve (AUC) determination of the single and combinatorial (multiplex) autophagy libraries. As a reference, a perfectly distributed library (ideal) is shown in grey. AUC values are indicated next to each library's identifier.

Supp. Figure 5. A-D) Pairwise sample correlation (Pearson's correlation coefficient), visualized as hierarchically clustered heatmaps (1-3) of pre- and post-FACS samples of autophagy enrichment screens with single (B) and combinatorial gRNA-targeting in autophagy blockage (C) and high-gates (D) on gRNA and gene level. Color code based on Pearson's correlation coefficient (rho) of normalized gRNA read counts. E) Analysis of ATG4B-associated guide pairs in high-gate post-FACS samples.

Supp. Figure 6. A-B) MAGeCK analysis of dedicated single (A) and multiplex-inherent single (B) gRNA autophagy screens between pre- and post-FACS samples with genes in red when matching cutoff criteria of $p$-value $\leq 0.05$. Screen-selective hits in blue.

917 Supp. Figure 7. A) Log2FC-analysis of targeting a single gene with one (single) or two 918 (double) gRNAs. The dotted diagonal line represents equal phenotypic strength, based 
920 genes for autophagy when targeted with one (yellow) or two (blue) gRNAs. Error bars

921 represent standard error of mean (SEM) over three biological replicates $(n=3)$. C) Density

922 plots of delta log2FC ( $\triangle \log 2 \mathrm{FC})$ value analyses of single essential genes for autophagy,

923 computed by MAX, SUM, MIN, MULT, and LOG models.

924

925 REFERENCES

926 1. Maddalo, D. et al. In vivo engineering of oncogenic chromosomal rearrangements with 927 the CRISPR/Cas9 system. Nature 516, 423-428 (2014).

928 2. Cong, L. et al. Multiplex genome engineering using CRISPR/Cas systems. Science (80-.

929 ). 339, 819-823 (2013).

930 3. Wong, A. S. L. et al. Multiplexed barcoded CRISPR-Cas9 screening enabled by

931 CombigeM. Proc. Natl. Acad. Sci. U. S. A. 113, 2544-2549 (2016).

932 4. Tzelepis, K. et al. A CRISPR Dropout Screen Identifies Genetic Vulnerabilities and

933 Therapeutic Targets in Acute Myeloid Leukemia. Cell Rep 17, 1193-1205 (2016).

934 5. Kabadi, A. M., Ousterout, D. G., Hilton, I. B. \& Gersbach, C. A. Multiplex CRISPR/Cas9-

935 based genome engineering from a single lentiviral vector. Nucleic Acids Res. 42, e147-

936 e147 (2014).

937 6. Sakuma, T., Nishikawa, A., Kume, S., Chayama, K. \& Yamamoto, T. Multiplex genome

938 engineering in human cells using all-in-one CRISPR/Cas9 vector system. Sci Rep 4,

$9395400(2014)$.

9407 7. Vad-Nielsen, J., Lin, L., Bolund, L., Nielsen, A. L. \& Luo, Y. Golden Gate Assembly of

941 CRISPR gRNA expression array for simultaneously targeting multiple genes. Cell. Mol.

$942 \quad$ Life Sci. 73, 4315-4325 (2016).

943 8. Zuckermann, M. et al. A novel cloning strategy for one-step assembly of multiplex

944 CRISPR vectors. Sci. Rep. 8, (2018).

945 9. Albers, J. et al. A versatile modular vector system for rapid combinatorial mammalian

946 genetics. J. Clin. Invest. 125, 1603-1619 (2015).

947 10. Haldeman, J. M. et al. Creation of versatile cloning platforms for transgene expression

948 and dCas9-based epigenome editing. Nucleic Acids Res. 47, e23-e23 (2018).

949 11. Breunig, C. T. et al. One step generation of customizable gRNA vectors for multiplex

950 CRISPR approaches through string assembly gRNA cloning (STAgR). PLoS One 13,

$951 \quad$ (2018).

952 12. Nissim, L., Perli, S. D., Fridkin, A., Perez-Pinera, P. \& Lu, T. K. Multiplexed and 
Programmable Regulation of Gene Networks with an Integrated RNA and CRISPR/Cas Toolkit in Human Cells. Mol. Cell 54, 698-710 (2014).

13. Minkenberg, B., Wheatley, M. \& Yang, Y. Chapter Seven - CRISPR/Cas9-Enabled Multiplex Genome Editing and Its Application. in Gene Editing in Plants (eds. Weeks, D. P. \& Yang, B. B. T.-P. in M. B. and T. S.) 149, 111-132 (Academic Press, 2017).

14. Vidigal, J. A. \& Ventura, A. Rapid and efficient one-step generation of paired gRNA CRISPR-Cas9 libraries. Nat Commun 6, 8083 (2015).

15. Shen, J. P. et al. Combinatorial CRISPR-Cas9 screens for de novo mapping of genetic interactions. Nat. Methods 14, 573-576 (2017).

16. Han, K. et al. Synergistic drug combinations for cancer identified in a CRISPR screen for pairwise genetic interactions. Nat. Biotechnol. 35, 463-474 (2017).

17. Mani, R., St Onge, R. P., Hartman, J. L., Giaever, G. \& Roth, F. P. Defining genetic interaction. Proc. Natl. Acad. Sci. U. S. A. 105, 3461-6 (2008).

18. Nijman, S. M. B. Synthetic lethality: General principles, utility and detection using genetic screens in human cells. FEBS Letters 585, 1-6 (2011).

19. Chan, D. A. \& Giaccia, A. J. Harnessing synthetic lethal interactions in anticancer drug discovery. Nature Reviews Drug Discovery 10, 351-364 (2011).

20. Ramkumar, P., Kampmann, M. \& Qian, C. CRISPR-based genetic interaction maps inform therapeutic strategies in cancer. Translational Cancer Research 7, S61-S67 (2018).

21. Ashworth, A. A Synthetic Lethal Therapeutic Approach: Poly(ADP) Ribose Polymerase Inhibitors for the Treatment of Cancers Deficient in DNA Double-Strand Break Repair. J. Clin. Oncol. 26, 3785-3790 (2008).

22. Helleday, T. The underlying mechanism for the PARP and BRCA synthetic lethality:

23. Cho, S. Y. et al. A novel combination treatment targeting BCL-XL and MCL1 for KRAS/BRAF-mutated and BCL2L1-amplified colorectal cancers. Mol. Cancer Ther. 16, 2178-2190 (2017).

24. Najm, F. J. et al. Orthologous CRISPR-Cas9 enzymes for combinatorial genetic screens.

983 25. Mereniuk, T. R. et al. Synthetic lethal targeting of PTEN-deficient cancer cells using selective disruption of polynucleotide kinase/phosphatase. Mol. Cancer Ther. 12, 2135-

986 26. Neshat, M. S. et al. Enhanced sensitivity of PTEN-deficient tumors to inhibition of 
FRAP/mTOR. Proc. Natl. Acad. Sci. U. S. A. 98, 10314-10319 (2001).

27. Zamanighomi, M. et al. GEMINI: a variational Bayesian approach to identify genetic interactions from combinatorial CRISPR screens. Genome Biol. 20, 137 (2019).

28. Klionsky, D. J. \& Emr, S. D. Autophagy as a regulated pathway of cellular degradation. Science 290, 1717-1721 (2000).

992 29. Dikic, I. \& Elazar, Z. Mechanism and medical implications of mammalian autophagy. Nature Reviews Molecular Cell Biology 19, 349-364 (2018).

994 30. Mizushima, N., Yoshimori, T. \& Levine, B. Methods in Mammalian Autophagy Research. $995 \quad$ Cell 140, 313-326 (2010).

31. Yoshii, S. R. \& Mizushima, N. Monitoring and measuring autophagy. International Journal of Molecular Sciences 18, (2017).

32. Morita, K. et al. Genome-wide CRISPR screen identifies TMEM41B as a gene required for autophagosome formation. J Cell Biol 217, 3817-3828 (2018).

33. Shoemaker, C. J. et al. CRISPR screening using an expanded toolkit of autophagy reporters identifies TMEM41B as a novel autophagy factor. PLoS Biol. 17, e2007044 (2019).

34. Moretti, F. et al. TMEM 41B is a novel regulator of autophagy and lipid mobilization. EMBO Rep. 19, (2018).

35. Jia, R. \& Bonifacino, J. S. Negative Regulation of Autophagy by UBA6-BIRC6-Mediated Ubiquitination of LC3. bioRxiv 8, 699124 (2019).

36. Orvedahl, A. et al. Autophagy genes in myeloid cells counteract IFNy-induced TNFmediated cell death and fatal TNF-induced shock. Proc. Natl. Acad. Sci. U. S. A. 116, 16497-16506 (2019).

37. Kerins, M. J. et al. Genome-Wide CRISPR Screen Reveals Autophagy Disruption as the Convergence Mechanism That Regulates the NRF2 Transcription Factor. Mol. Cell. Biol. 39, (2019).

39. Potting, C. et al. Genome-wide CRISPR screen for PARKIN regulators reveals transcriptional repression as a determinant of mitophagy. Proc. Natl. Acad. Sci. 115, 201711023 (2017).

40. Hoshino, A. et al. The ADP/ATP translocase drives mitophagy independent of nucleotide exchange. Nature 575, 375-379 (2019).

41. Heo, J. M. et al. Integrated proteogenetic analysis reveals the landscape of a 
mitochondrial-autophagosome synapse during PARK2-dependent mitophagy. Sci. Adv. 5, (2019).

42. Towers, C. G. \& Thorburn, A. Therapeutic Targeting of Autophagy. EBioMedicine 14, 1523 (2016).

43. Levy, J. M. M., Towers, C. G. \& Thorburn, A. Targeting autophagy in cancer. Nature Reviews Cancer 17, 528-542 (2017).

44. Galluzzi, L., Bravo-San Pedro, J. M., Levine, B., Green, D. R. \& Kroemer, G. Pharmacological modulation of autophagy: Therapeutic potential and persisting obstacles. Nature Reviews Drug Discovery 16, 487-511 (2017).

45. Wegner, M. et al. Circular synthesized CRISPR/Cas gRNAs for functional interrogations in the coding and noncoding genome. Elife 8, (2019).

46. Dang, Y. et al. Optimizing sgRNA structure to improve CRISPR-Cas9 knockout efficiency. Genome Biol. 16, 280 (2015).

47. Cross, B. C. S. et al. Increasing the performance of pooled CRISPR-Cas9 drop-out screening. Sci. Rep. 6, 1-8 (2016).

49. Imkeller, K., Ambrosi, G., Boutros, M. \& Huber, W. Gscreend: Modelling asymmetric count ratios in CRISPR screens to decrease experiment size and improve phenotype detection. Genome Biol. 21, 53 (2020).

50. Hart, T. et al. High-Resolution CRISPR Screens Reveal Fitness Genes and GenotypeSpecific Cancer Liabilities. Cell 163, 1515-1526 (2015).

1043

51. Doench, J. G. et al. Optimized sgRNA design to maximize activity and minimize off-target effects of CRISPR-Cas9. Nat Biotechnol 34, 184-191 (2016).

52. Kim, E. \& Hart, T. Improved analysis of CRISPR fitness screens and reduced off-target effects with the BAGEL2 gene essentiality classifier. bioRxiv 2020.05.30.125526 (2020). doi:10.1101/2020.05.30.125526

53. Li, W. et al. MAGeCK enables robust identification of essential genes from genome-scale CRISPR/Cas9 knockout screens. Genome Biol. 15, 554 (2014).

54. Gonatopoulos-Pournatzis, T. et al. Genetic interaction mapping and exon-resolution functional genomics with a hybrid Cas9-Cas12a platform. Nat. Biotechnol. 38, 638-648 (2020).

55. Ong, S. H., Li, Y., Koike-Yusa, H. \& Yusa, K. Optimised metrics for CRISPR-KO screens with second-generation gRNA libraries. Sci. Rep. 7, 7384 (2017). 
56. Kaizuka, T. et al. An Autophagic Flux Probe that Releases an Internal Control. Mol. Cell 64, 835-849 (2016).

57. Dejesus, R. et al. Functional CRISPR screening identifies the ufmylation pathway as a regulator of SQSTM1/p62. Elife 5, (2016).

58. Goodwin, J. M. et al. Autophagy-Independent Lysosomal Targeting Regulated by ULK1/2-FIP200 and ATG9. Cell Rep. 20, 2341-2356 (2017).

59. Peets, E. M. et al. Minimized double guide RNA libraries enable scale-limited CRISPR/Cas9 screens. bioRxiv 859652 (2019). doi:10.1101/859652

60. Costanzo, M. et al. A global genetic interaction network maps a wiring diagram of cellular function. Science 353, aaf1420 (2016).

61. Xie, X., Le, L., Fan, Y., Lv, L. \& Zhang, J. Autophagy is induced through the ROS-TP53DRAM1 pathway in response to mitochondrial protein synthesis inhibition. Autophagy 8 , 1071-1084 (2012).

62. Gonçalves, E. et al. Minimal genome-wide human CRISPR-Cas9 library. bioRxiv 848895 (2019). doi:10.1101/848895

1070

63. Dede, M., McLaughlin, M., Kim, E. \& Hart, T. Multiplex enCas12a screens show functional buffering by paralogs is systematically absent from genome-wide CRISPR/Cas9 knockout screens. bioRxiv 2020.05.18.102764 (2020). doi:10.1101/2020.05.18.102764

64. Folkerts, H. et al. Inhibition of autophagy as a treatment strategy for p53 wild-type acute myeloid leukemia. Cell Death Dis. 8, e2927 (2017).

65. Rogov, V., Dötsch, V., Johansen, T. \& Kirkin, V. Interactions between Autophagy Receptors and Ubiquitin-like Proteins Form the Molecular Basis for Selective Autophagy. Molecular Cell 53, 167-178 (2014).

66. Chen, B. et al. Dynamic imaging of genomic loci in living human cells by an optimized CRISPR/Cas system. Cell 155, 1479-1491 (2013).

67. Martin, M. Cutadapt removes adapter sequences from high-throughput sequencing reads. EMBnet.journal 17, 10 (2011).

68. Langmead, B. \& Salzberg, S. L. Fast gapped-read alignment with Bowtie 2. Nat. Methods 9, 357-359 (2012).

69. Waskom, M. et al. mwaskom/seaborn: v0.10.1 (April 2020). (2020).

1087 70. Shannon, P. et al. Cytoscape: A software Environment for integrated models of biomolecular interaction networks. Genome Res. 13, 2498-2504 (2003). 
bioRxiv preprint doi: https://doi.org/10.1101/2020.07.28.201152; this version posted July 28, 2020. The copyright holder for this preprint (which

was not certified by peer review) is the author/funder, who has granted bioRxiv a license to display the preprint in perpetuity. It is made available under aCC-BY-NC-ND 4.0 International license.

1089 71. Brinkman, E. K., Chen, T., Amendola, M. \& van Steensel, B. Easy quantitative

1090 assessment of genome editing by sequence trace decomposition. Nucleic Acids Res $\mathbf{4 2}$,

1091 e168 (2014).

1092 


\section{Figure 1}

A bioRxiv preprint doi: https://doi.org/10.1101/2020.07.28.201152; this version posted July 28, 2020. The copyright holder for this preprint (which was not certified by peer review) is the author/funder, who has granted bioRxiv a license to display the preprint in perpetuity. It is made

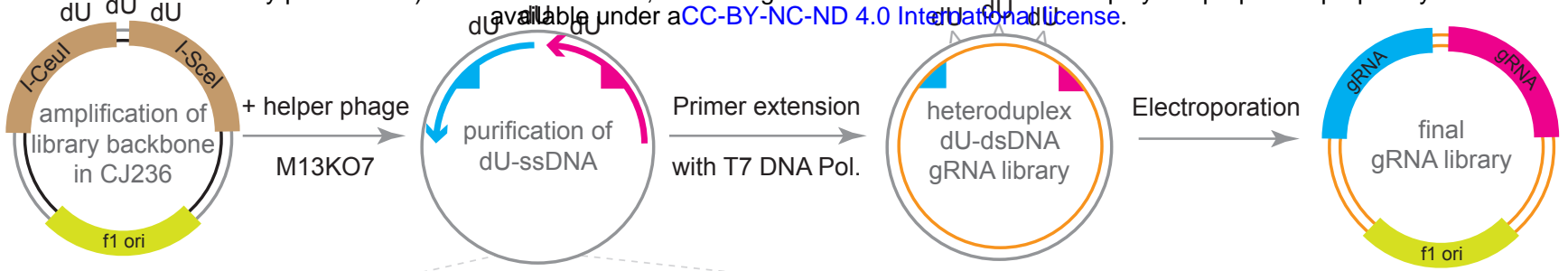
WT
new
f-origin (phagemid)
new gRNA Primer(s)
$\wedge$ dU mismatch

LTR $\Psi$ RRE cPPT gRNA tracrV2 gRNA tracrWT L

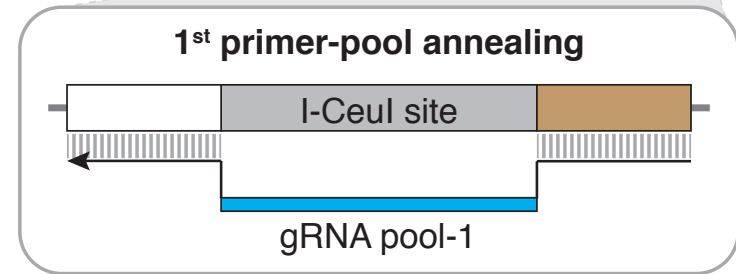

B

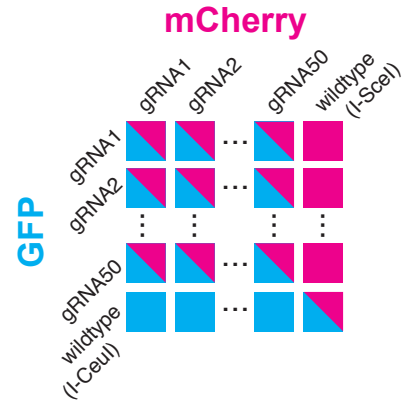

GFP and mCherry single libraries (one site is wildtype)

Combinatorial library (2601 constructs)

50 gRNAs per gene

D

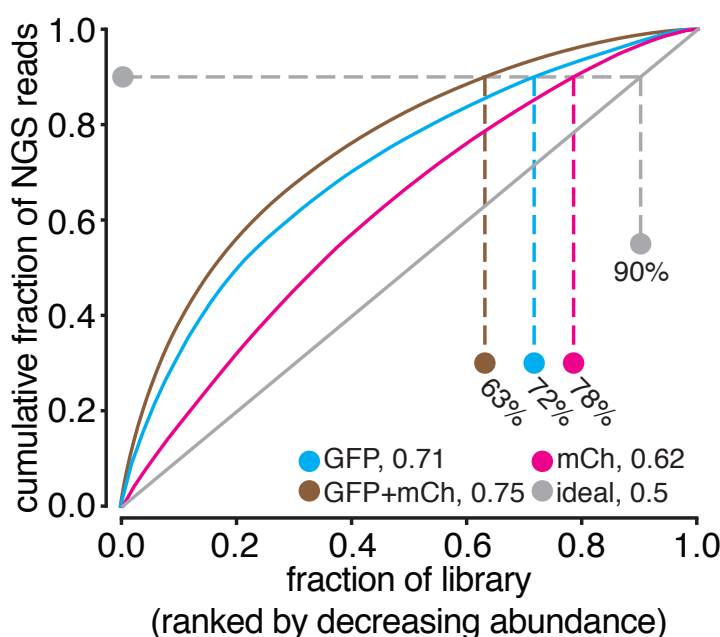

E
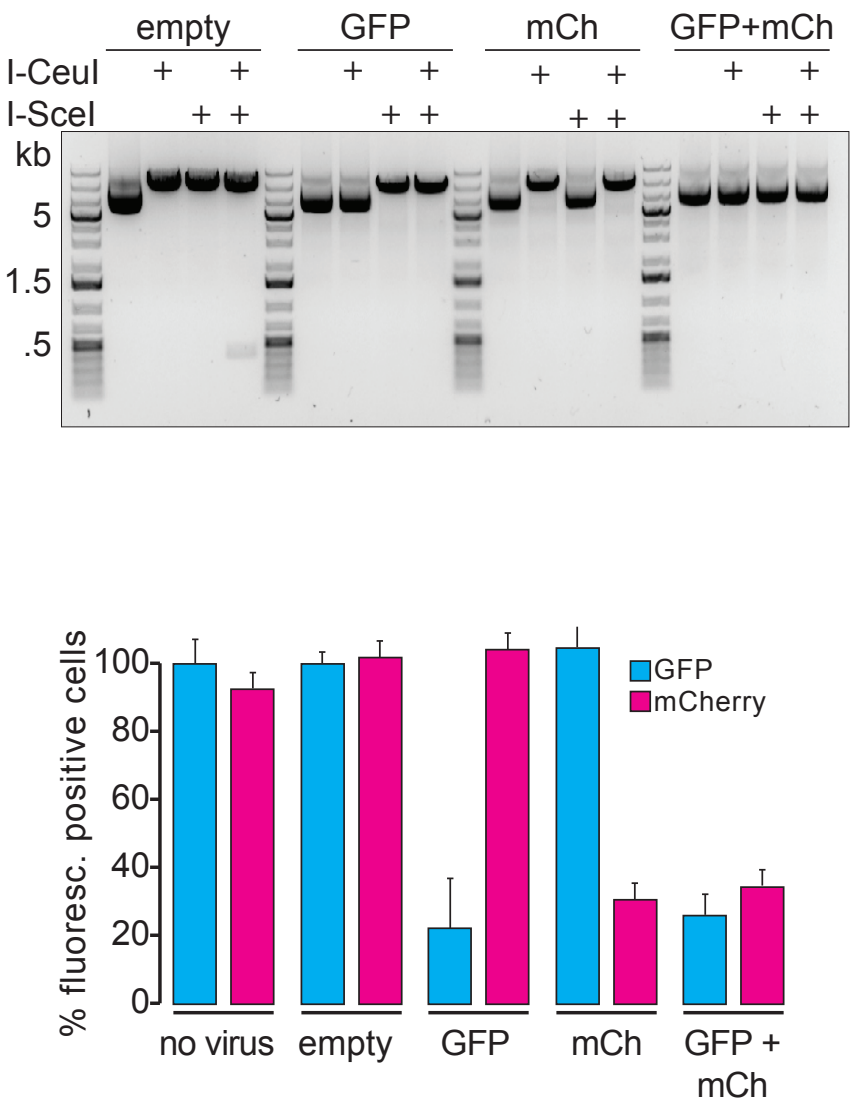


\section{Figure 2}

A bioRxiv preprint doi: https://doi.org/10.1101/2020.07.201152; this version posted July 202020 2020 The copyright holder for this preprint (which A was not certified by peer review) is the author/fun , who has granted bioRxiv a licerlse to display the preprint in perpetuity. It is made

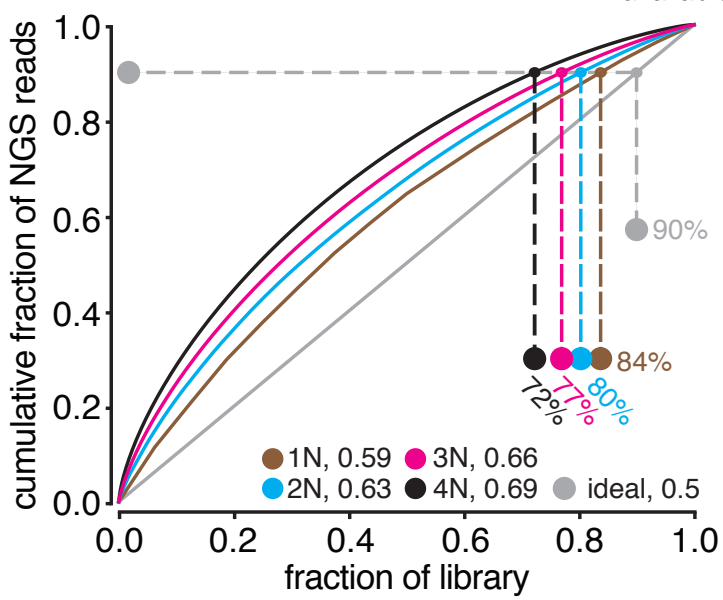

(ranked by decreasing abundance)

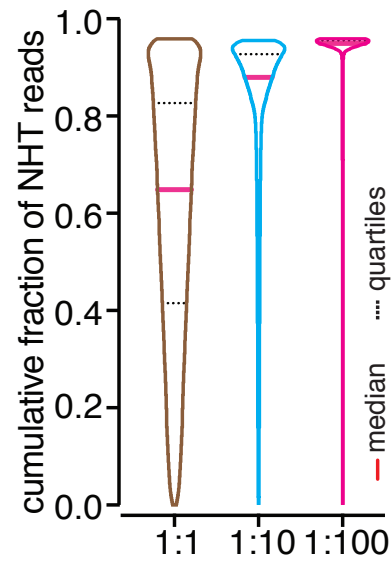

1:10 library

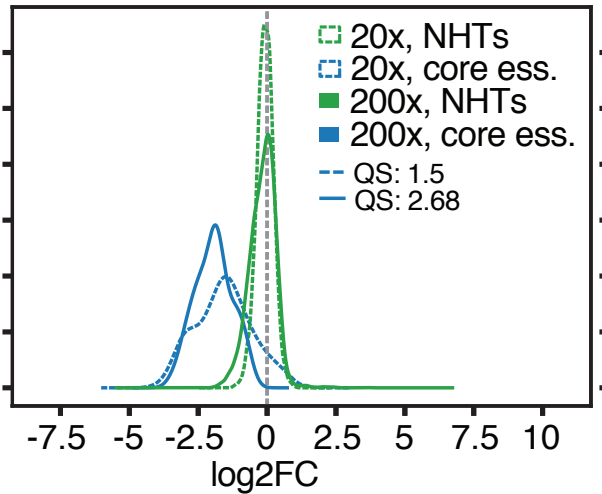

$F$

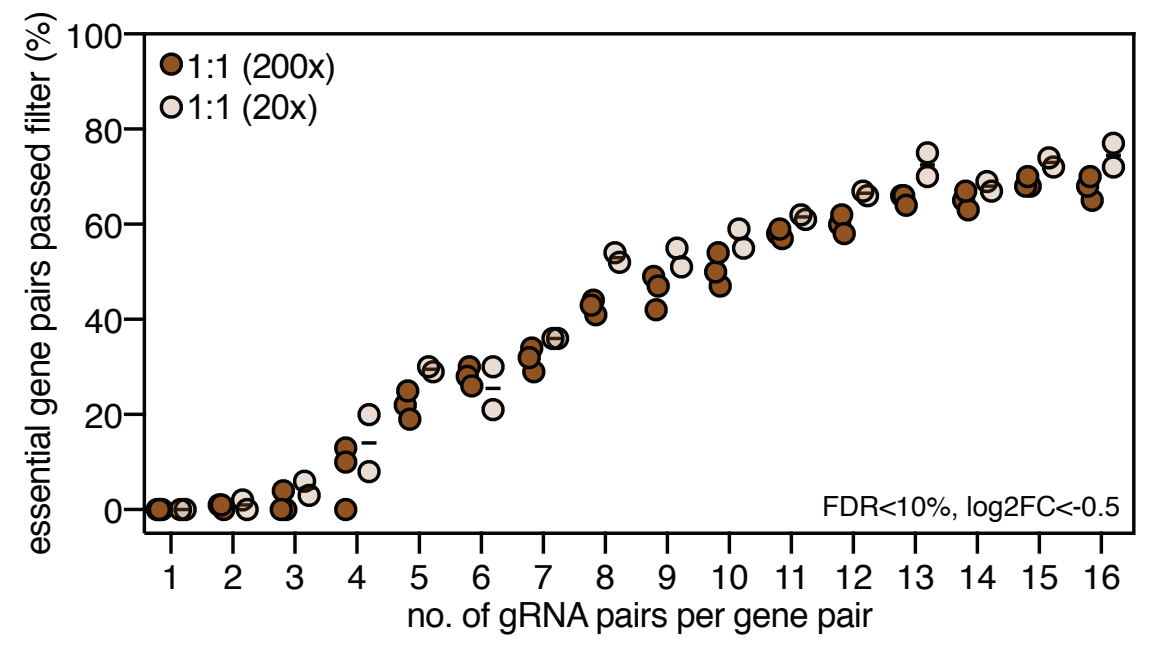




\section{Figure 3}

A bioRxiv preprint doi: https://doi.d 10.1101/2020.07.28.201152; this version posted July 28, 2020. The copvight holdet for this preprint (which was not certified by peer review) is the author/funder, who has granted bioRxiv a license to display the preprint in perpetuity. It is made core autophagy

(64 genes, 282 guides)

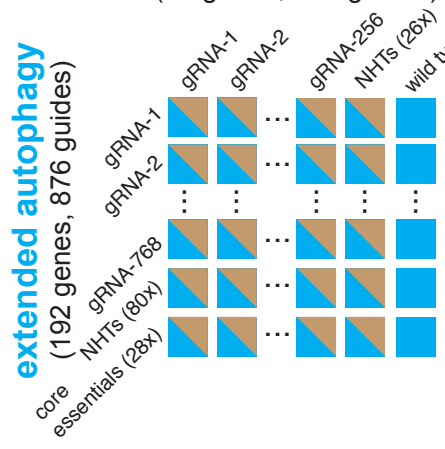
available under aCC-BY-NC-ND 4.0 International license.

$$
\text { Cov. } 1000 x(s), 2 x
$$

Cov. 20x (mpx), 3x MOI 0.5

D

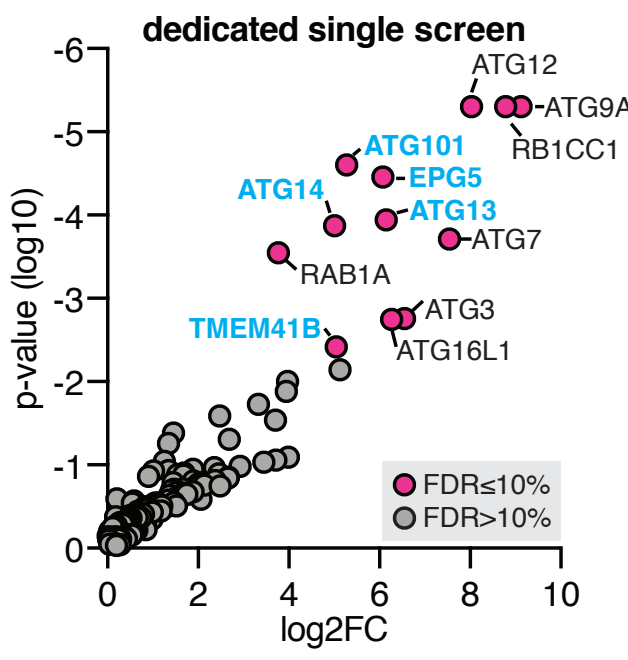

E

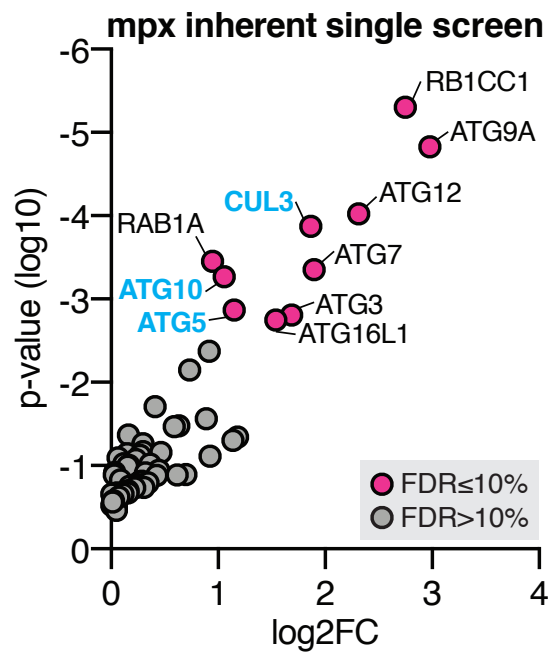

F

\section{hTERT-RPE1}

(SpCas9, GFP-LC3B-RFP)
+Torin 1

12 days

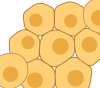

FACS

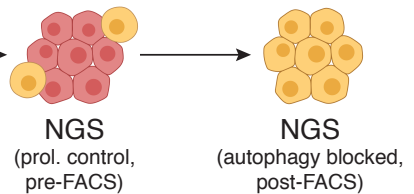

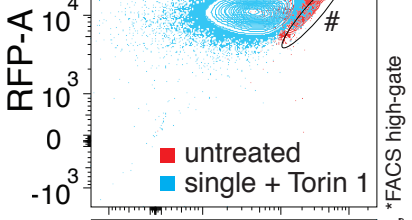

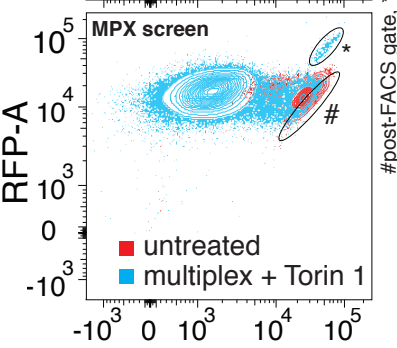
GFP-A

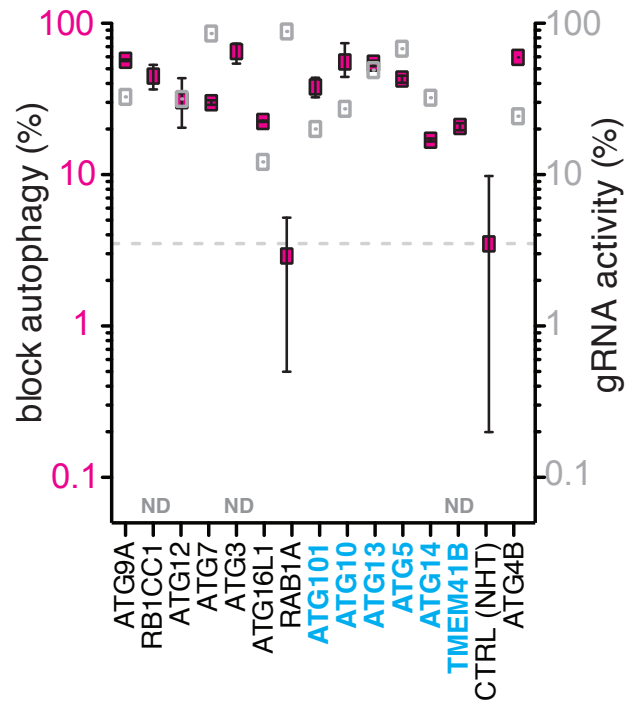


A bioRxiv preprint doi: https://doi.org/10.110 020.07.28.201152; this version posted July 28, 2020.The copyright holder for this preprint (which

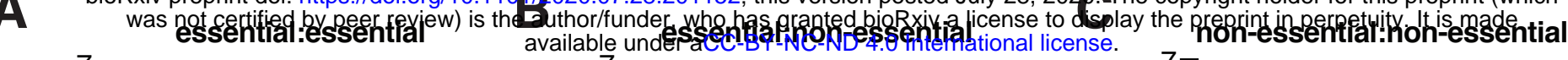

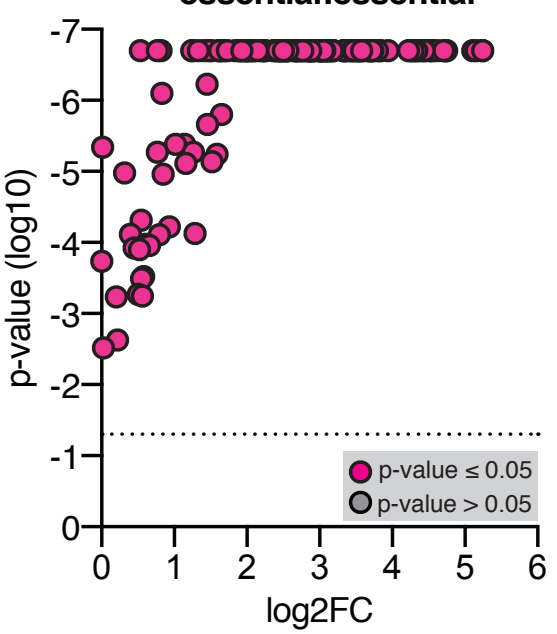

D

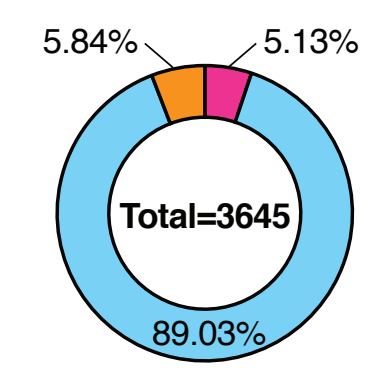

\#187, ess:ess

\#3645, ess:non-ess \#213, non-ess:non-ess

H
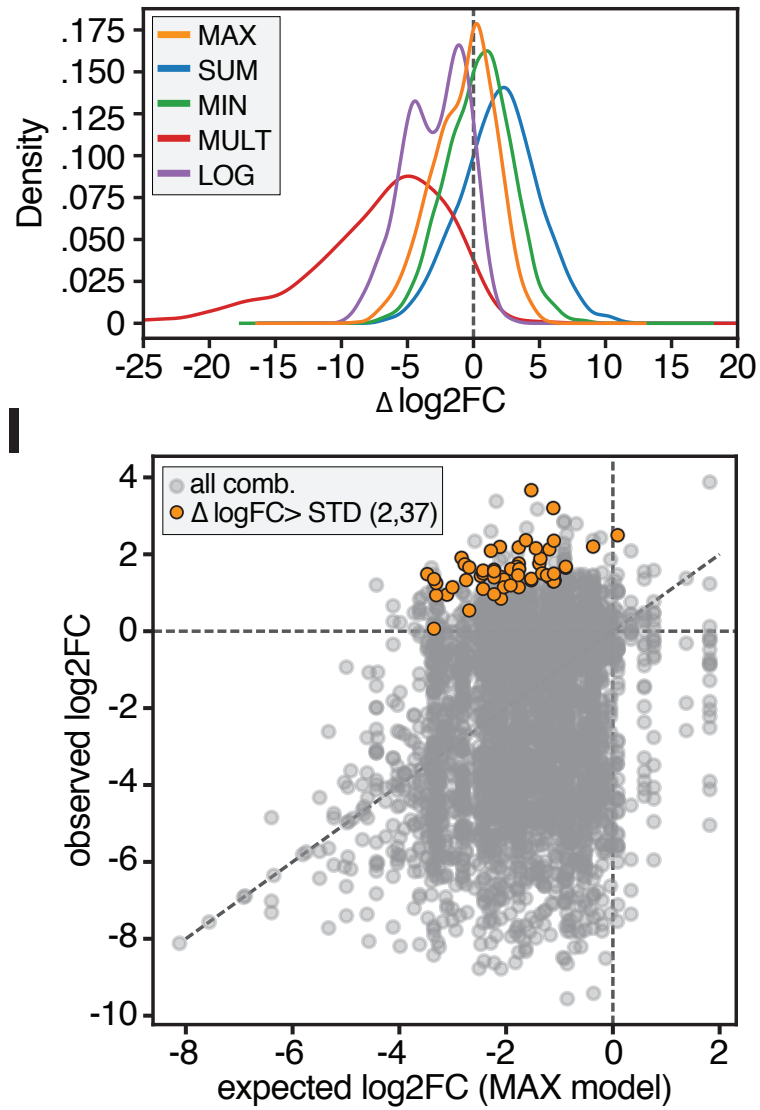

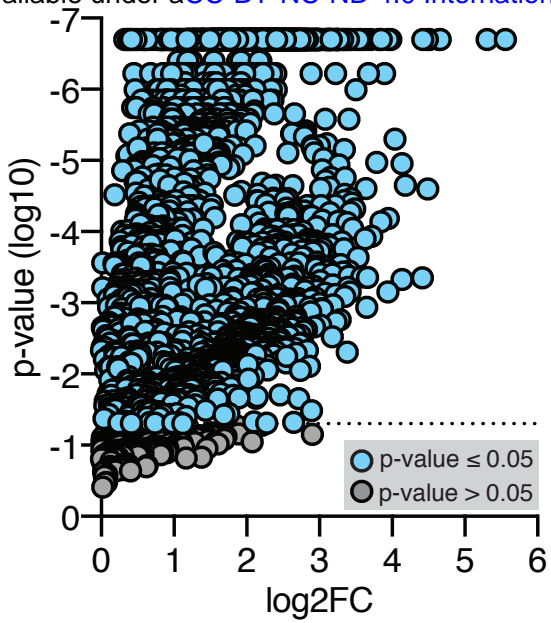

E
F

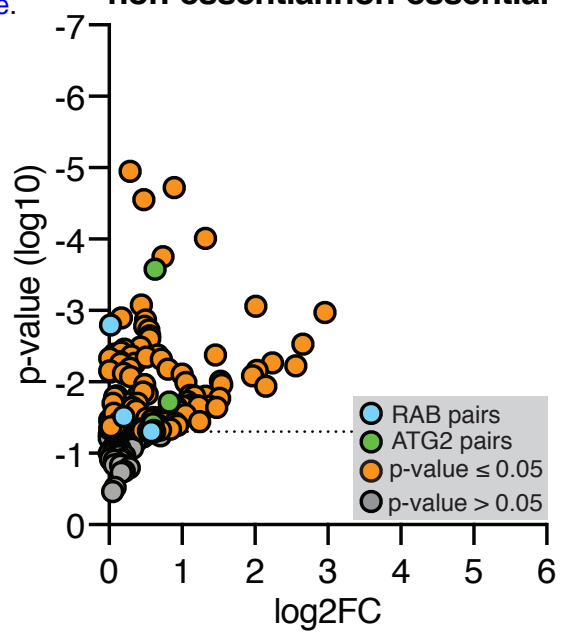

G
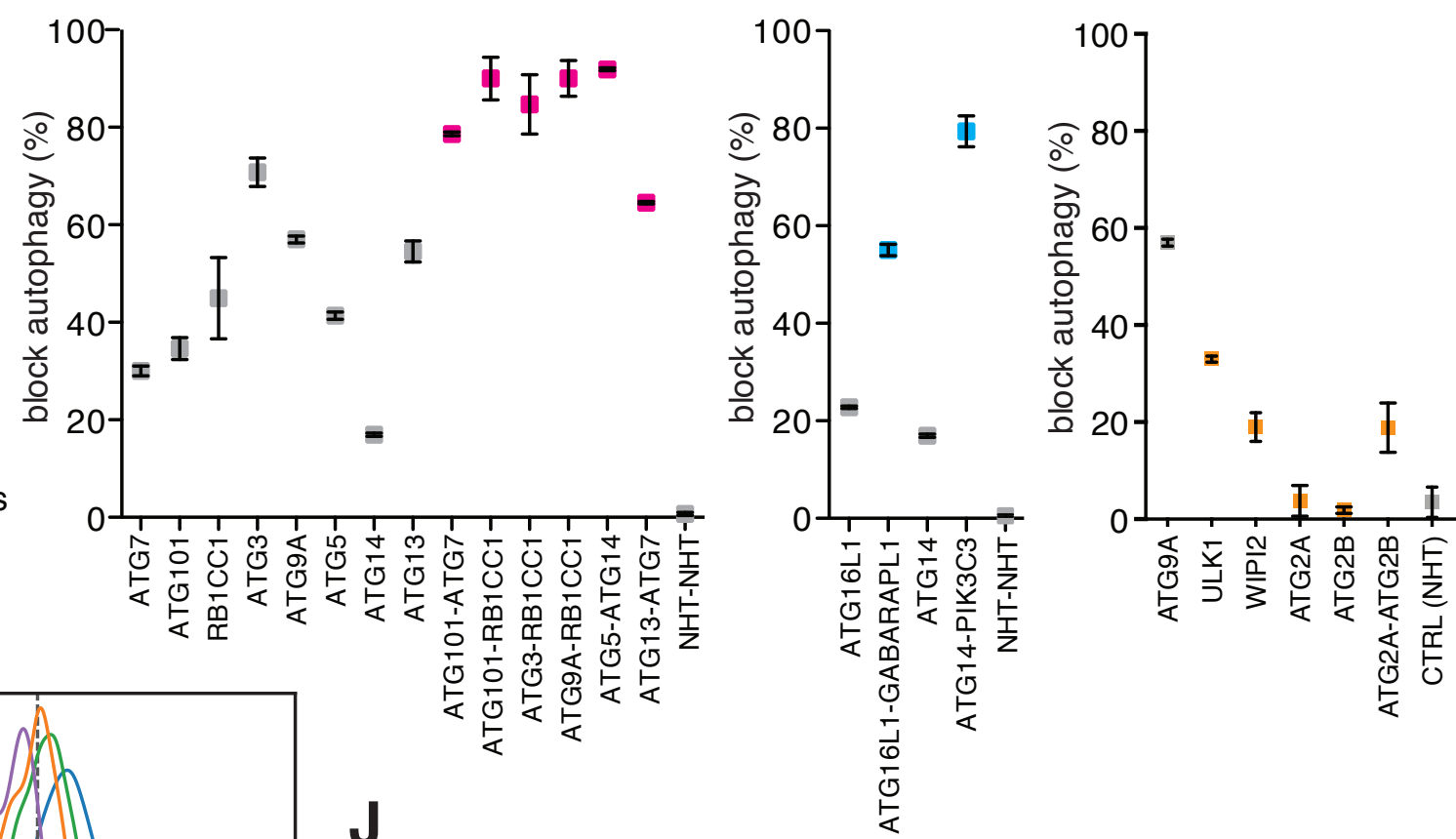

$\mathbf{J}$
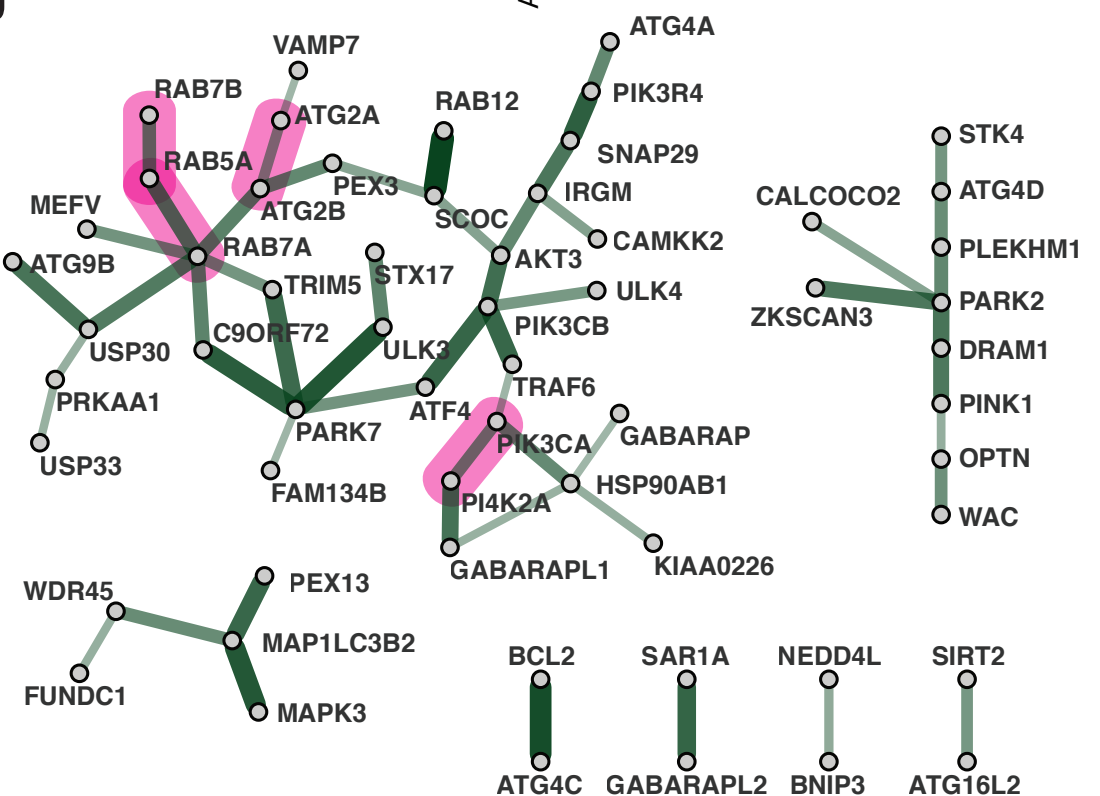

SQSTM10 $\stackrel{\text { CTSB }}{\mathrm{O}}$ O WIPI1

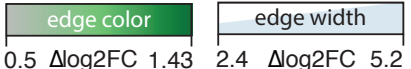




\section{Supp. Figure 1}

bioRxiv preprint doi: https://doi.org/10.1101/2020.07.28.201152; this version posted July 28, 2020. The copyright holder for this preprint (which A was not certified by peer review) is the auth funder, who has granted bioRxiv a lense to display the preprint in perpetuity. It is made availatole under aCC-BY-NC-ND 4.0 International license.
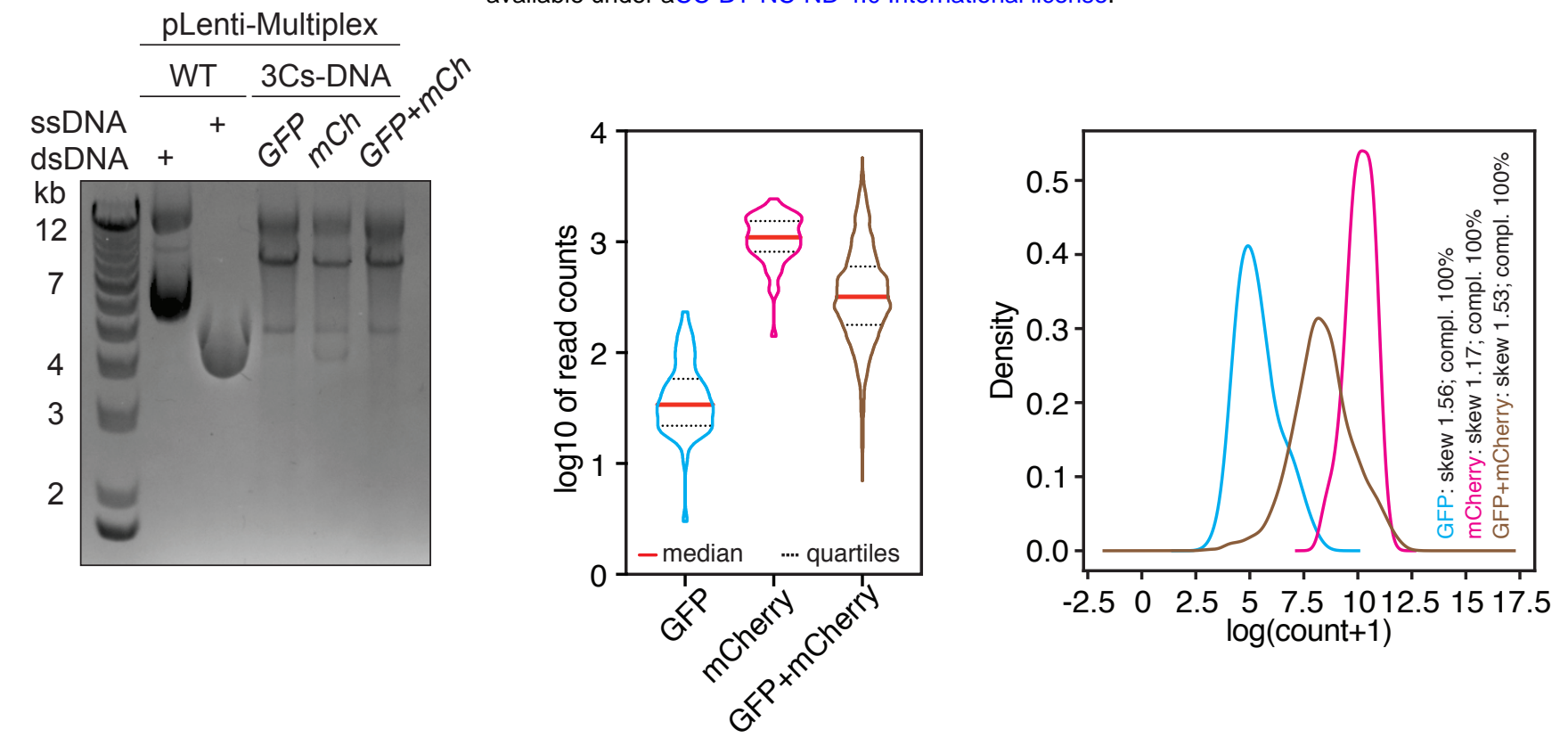


\section{Supp. Figure 2}

A bioRxiv preprint doi: https://doi.org/10.1101/2020.07.28. 1152 ; this version posted July 28, 2020. The copyright holder for this preprint (which was not certified by peer review) is the author/funder, who has granted bioRxiv a license to display the preprint in perpetuity. It is made
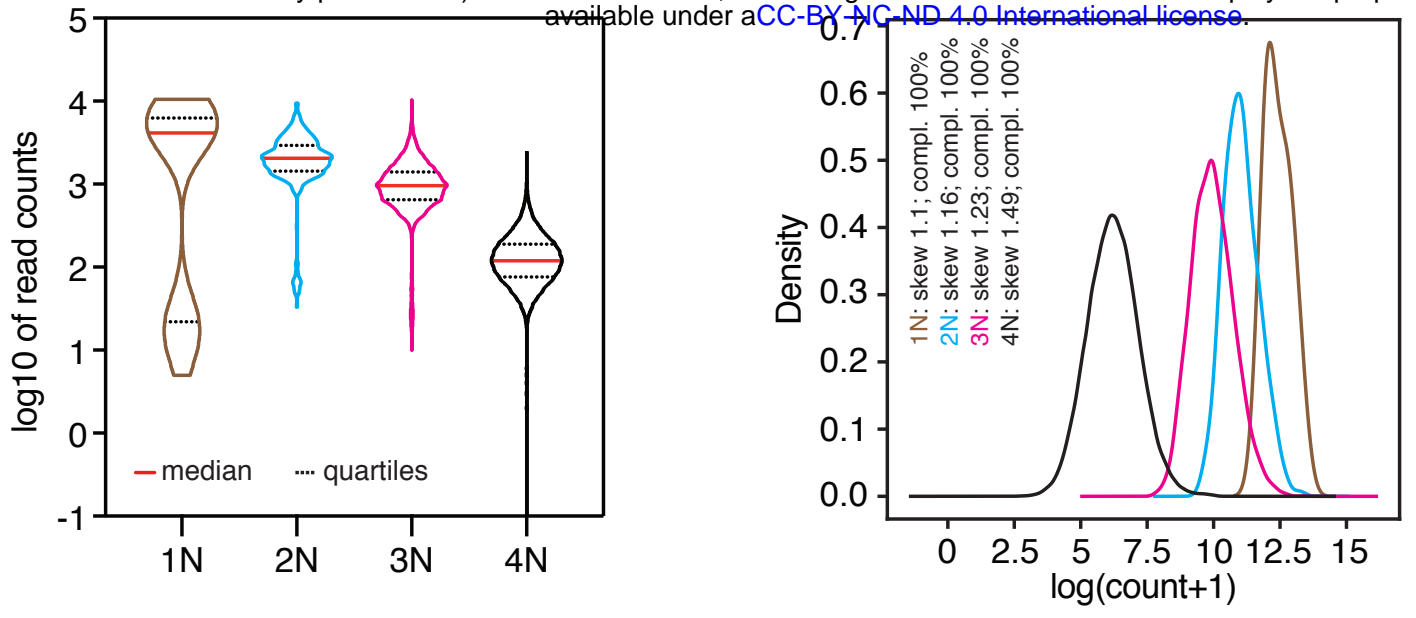

C
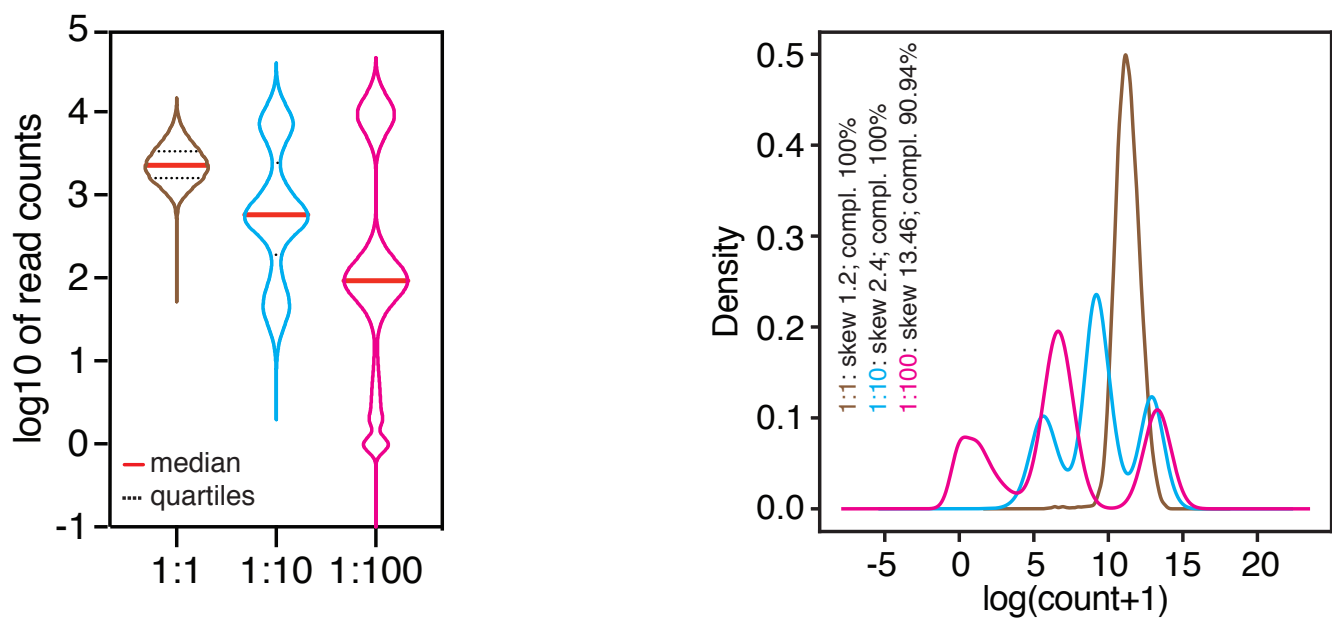


\section{Supp. Figure 3}

A bioRxiv preprint doi: https://doi.org/10.1101/2020.07.28.201152; this version posted July 28, 2020. The copyright holder for this preprint (which was not certified by.9peer review) is the author/funder, who has granted bioRxiv a license to display the preprint in perpetuity. It is made

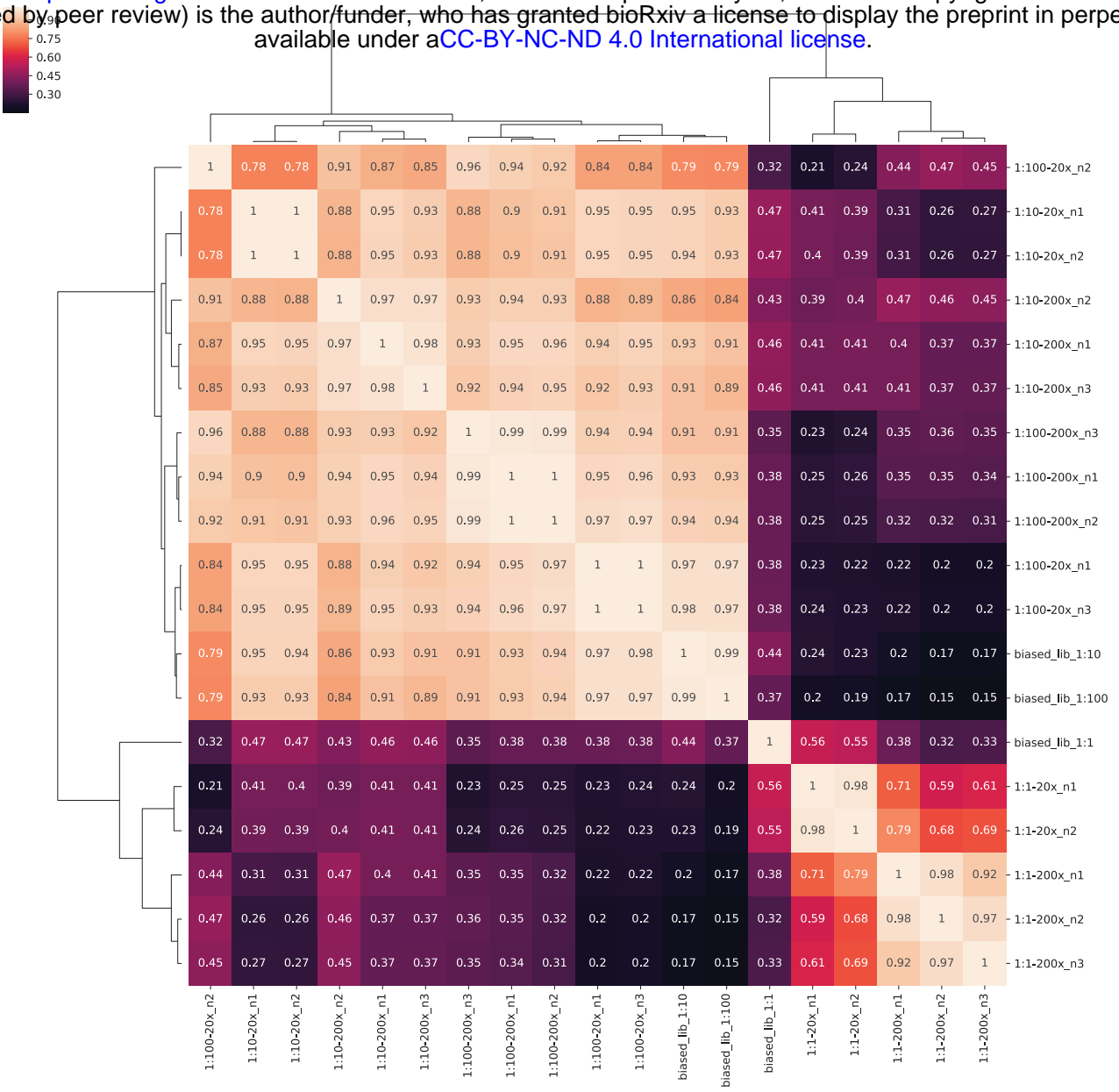

B

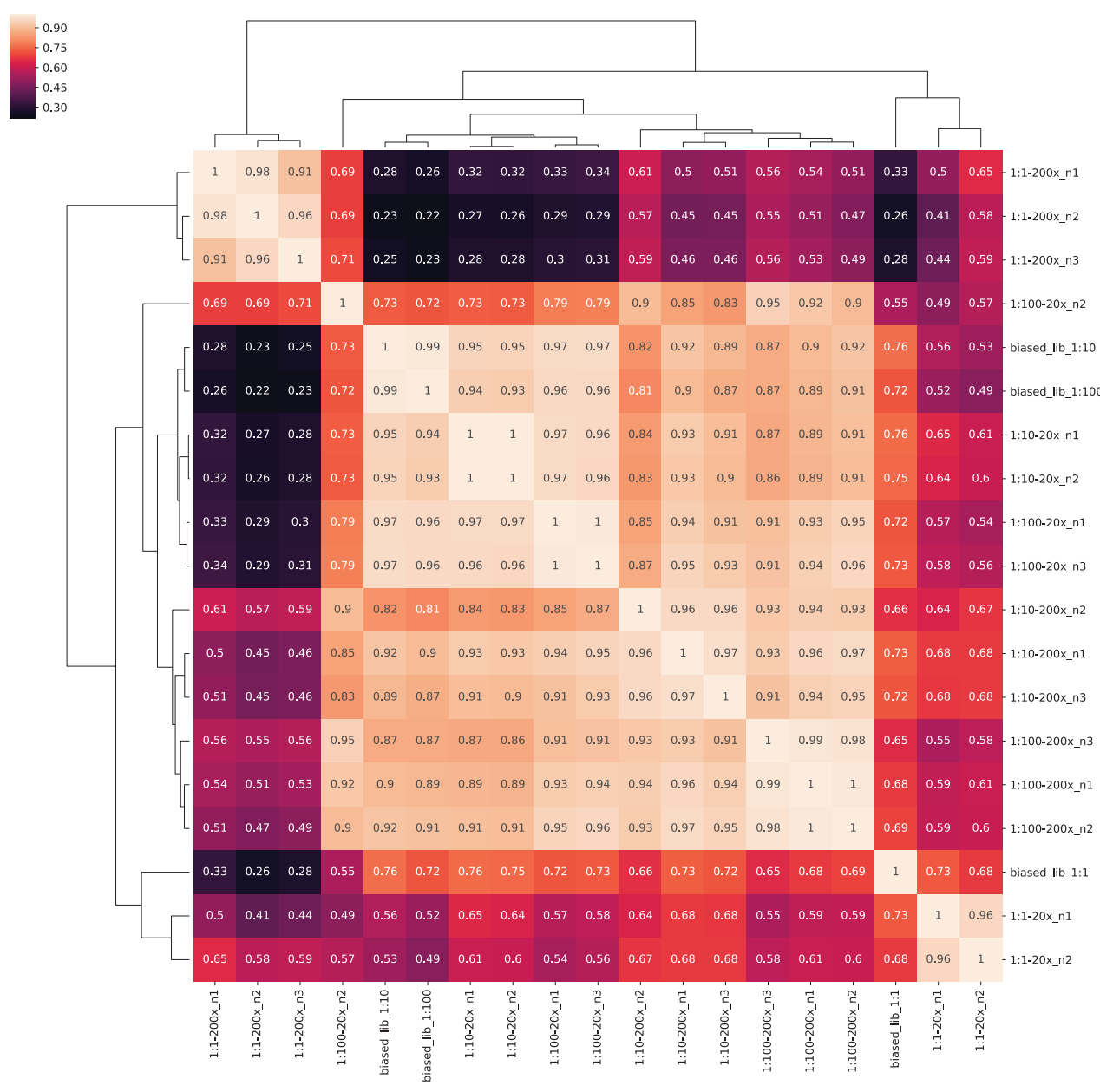




\section{Supp. Figure 4}

bioRxiv preprint doi: https://doi.org/10.1101/2020.07.28.201152; this version posted July 28, 2020. The copyright holder for this preprint (which was not certified by peer review) is the author/funder, who has granted bioRxiv a license to display the preprint in perpetuity. It is made available under aCC-BY-NC-ND 4.0 International license.
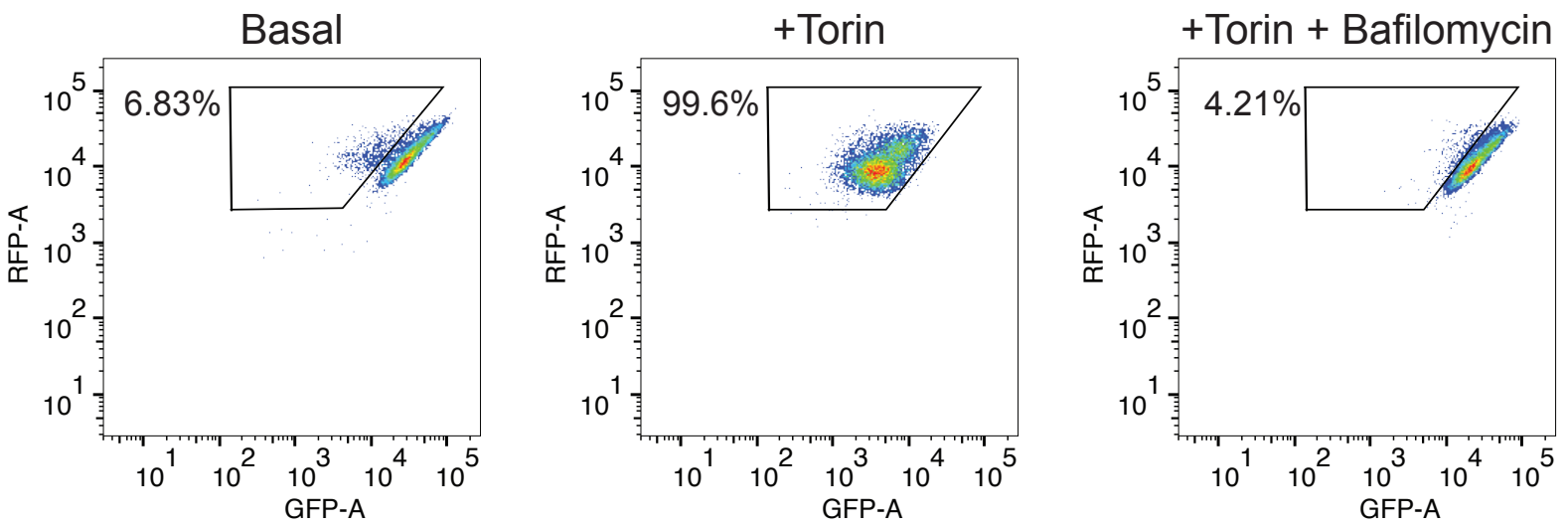

B
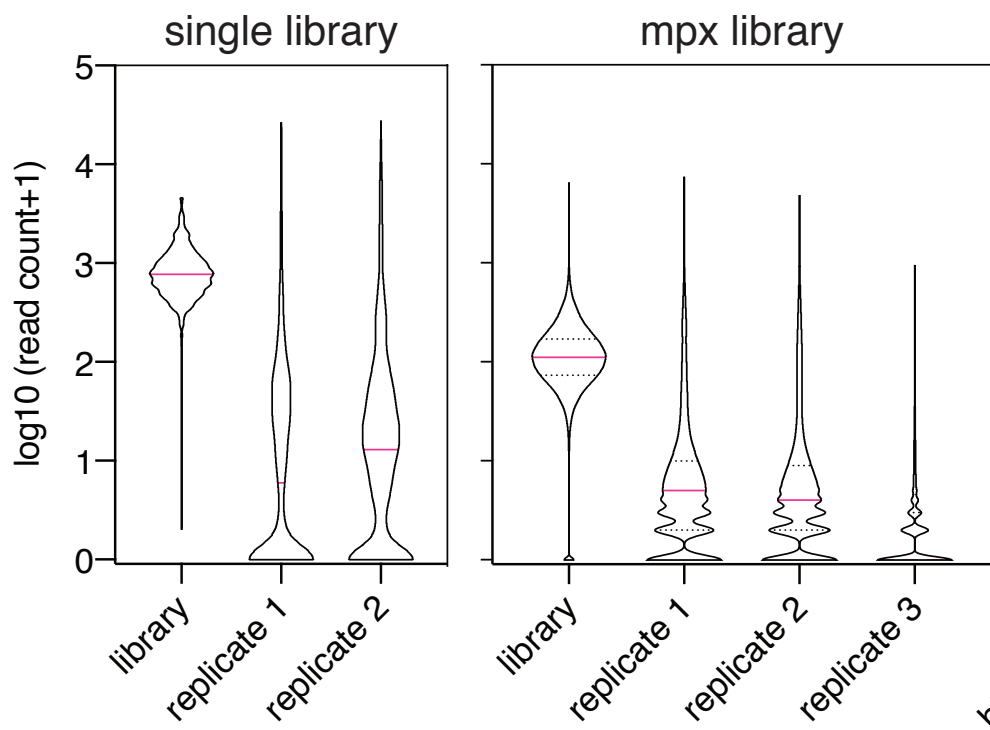

high-gates

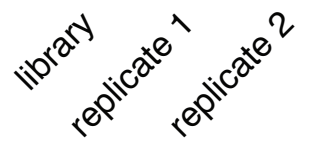

C
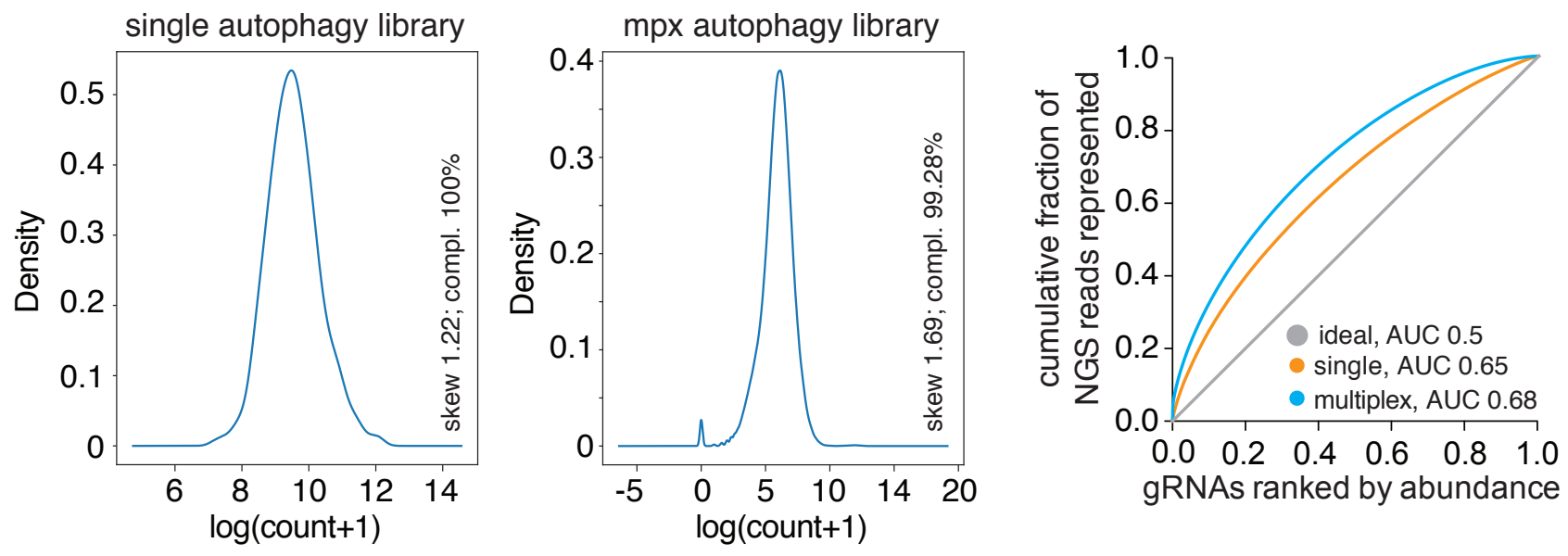


\section{Supp. Figure 5}

A bioRxiv preprint doi: thps://doi.org/181101/20280728201152; this versign posted July 28, 2020. The copyright holder for this preprint (which

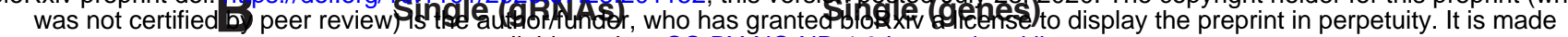
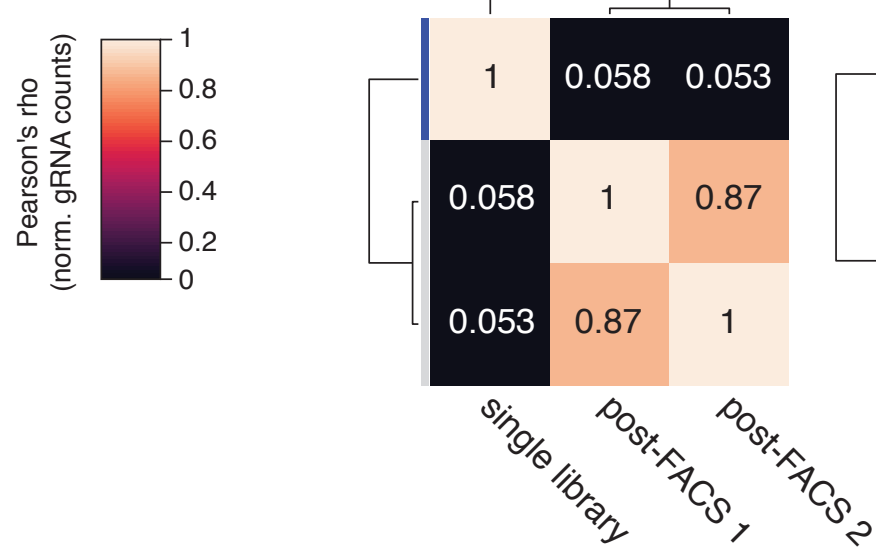

C

Multiplex (gRNAs)
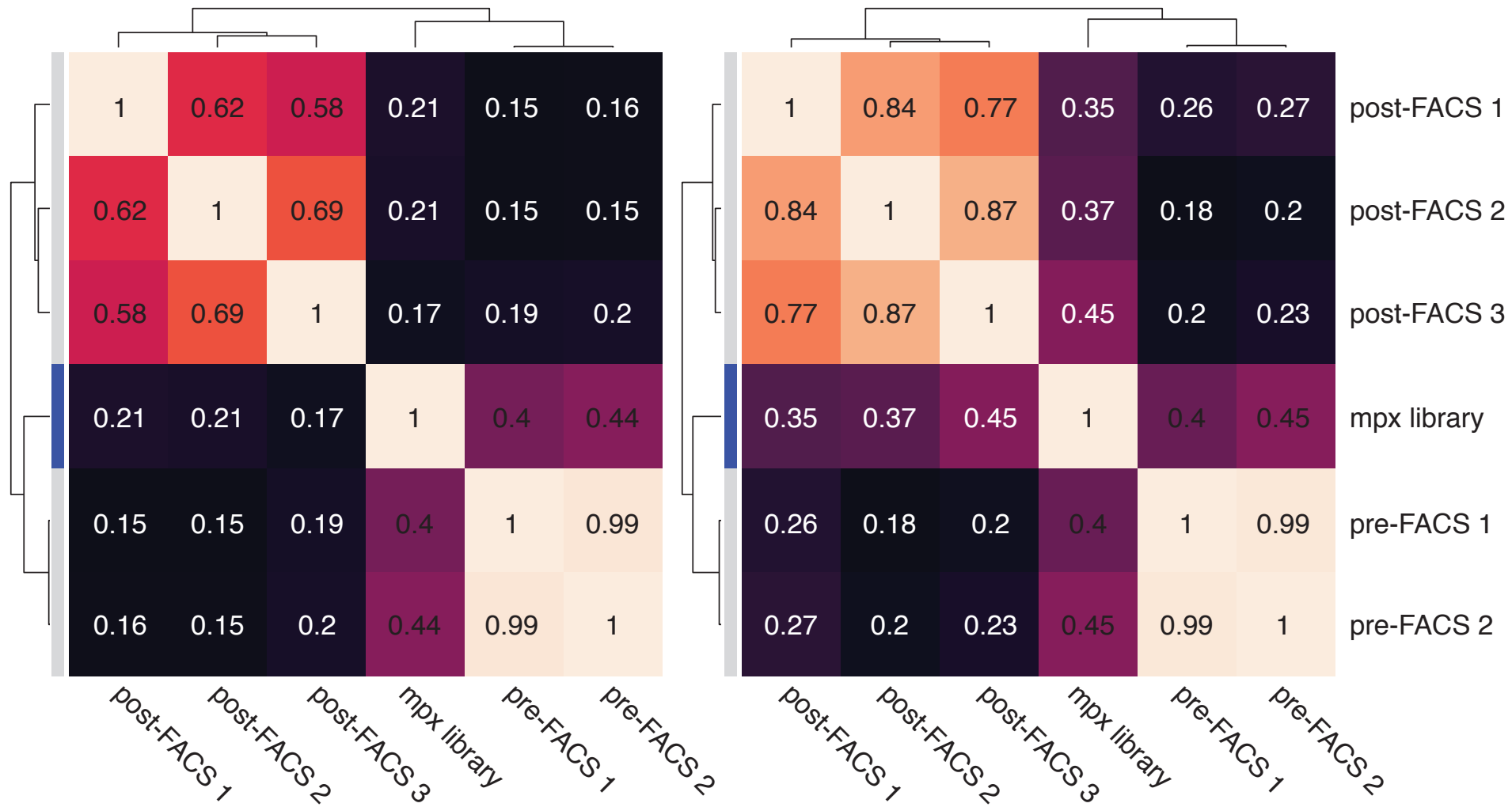

Multiplex (genes)

D

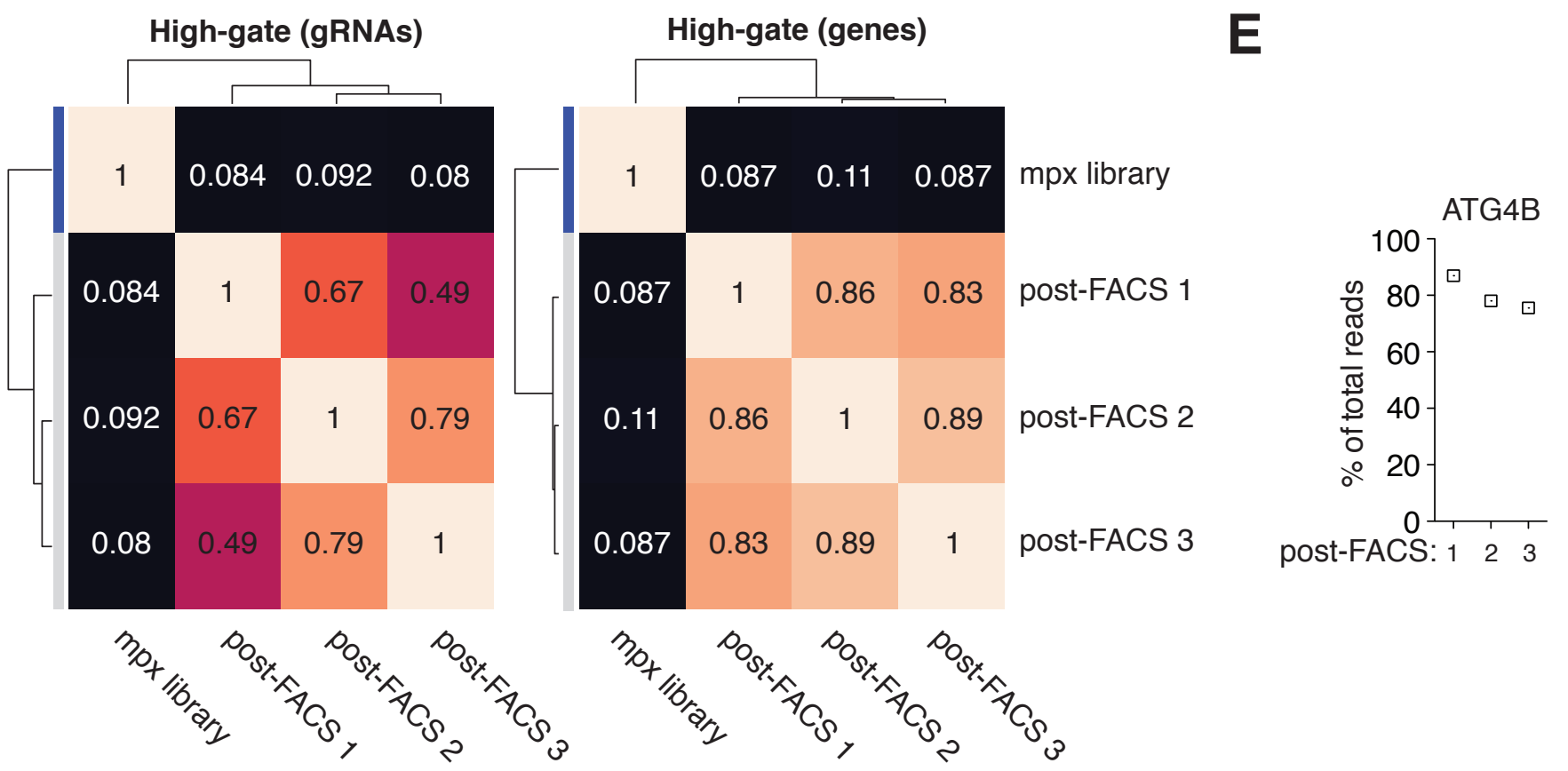




\section{Supp. Figure 6}

A bioRxiv preprint doi: https://doi.org/10.1101/2020.07.28.201152; this version posted July 28, 2020. The copyright holder for this preprint (which was not certified by peer review) is the 3 hor/funder, who has granted bioRxiv a license to display the preprint in perpetuity. It is made dedicated single screen
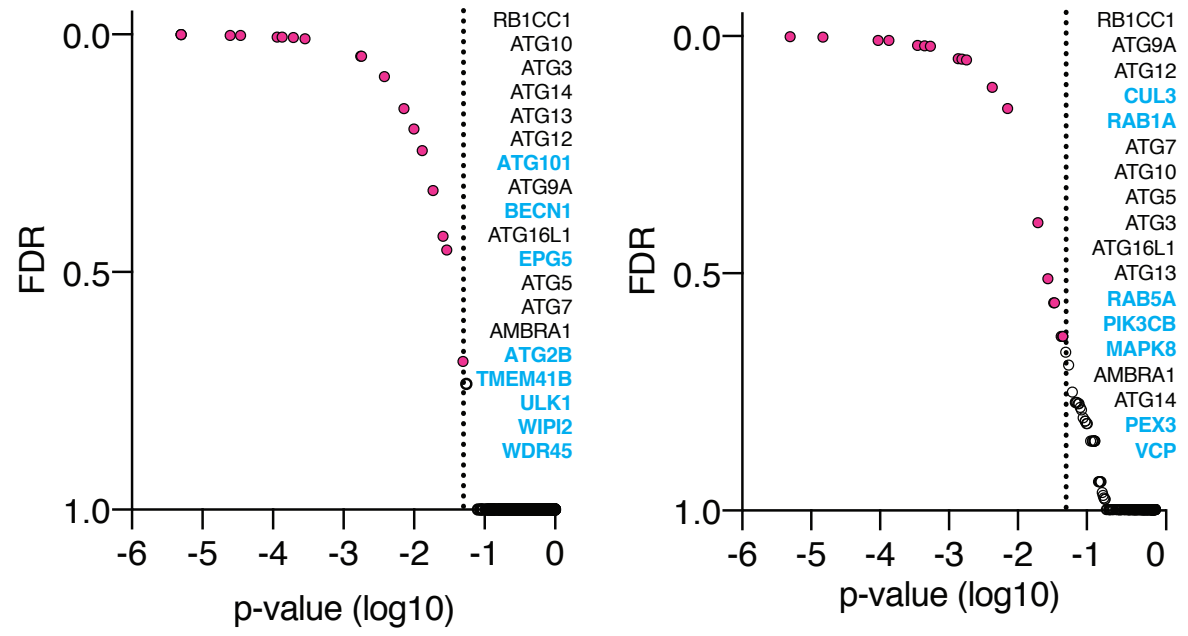


\section{Supp. Figure 7}

A bioRxiv preprint doi: https://doi.org/10.1101/2020.07.28 1152 ; this version posted July 28, 2020. The copyright holder for this preprint (which was not certified by peer review) is the author/fund who has granted bioRxiv a license to display the preprint in perpetuity. It is made available under aCC-BY-NC-ND 4.0 International license.

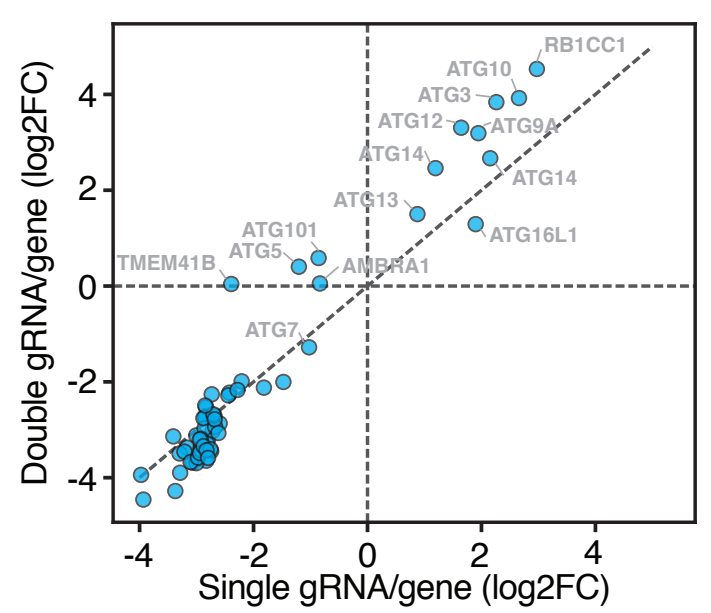

C

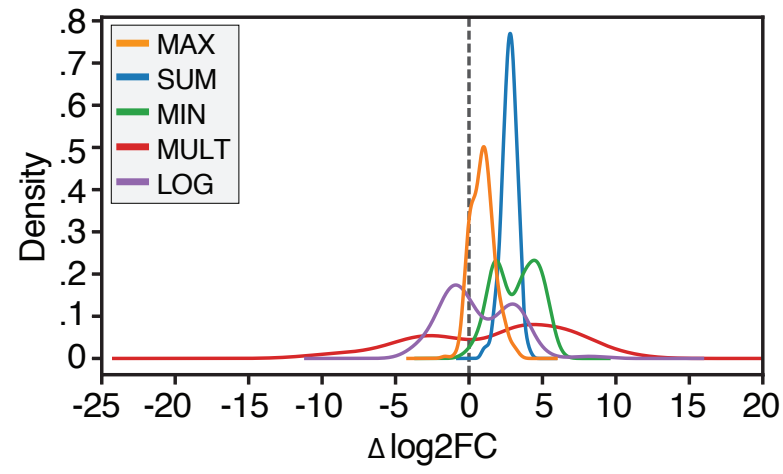

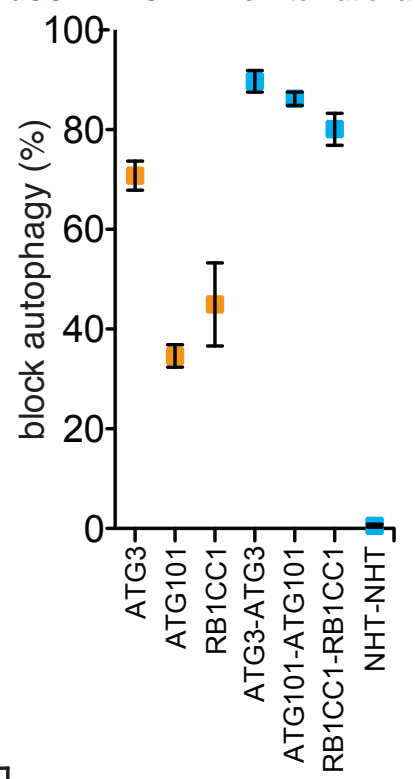

